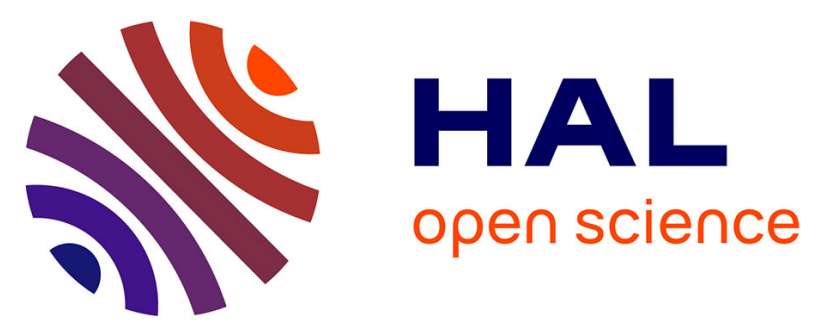

\title{
On structural finite element modeling strategies and their influence on the optimization of final constructability of reinforced concrete structures
}

Guillaume Hervé-Secourgeon, Estelle Hervé-Secourgeon, Marina Bottoni, François Voldoire, Mihaja Razafimbelo, Fabrice Gatuingt, Cécile Oliver Oliver-Leblond, Tulio Honorio, Ahmad Kameh, Souheil Habib, et al.

\section{To cite this version:}

Guillaume Hervé-Secourgeon, Estelle Hervé-Secourgeon, Marina Bottoni, François Voldoire, Mihaja Razafimbelo, et al.. On structural finite element modeling strategies and their influence on the optimization of final constructability of reinforced concrete structures. Nuclear Engineering and Design, 2021, 385, pp.111541. 10.1016/j.nucengdes.2021.111541 . hal-03420820

\section{HAL Id: hal-03420820 https://hal.science/hal-03420820}

Submitted on 9 Nov 2021

HAL is a multi-disciplinary open access archive for the deposit and dissemination of scientific research documents, whether they are published or not. The documents may come from teaching and research institutions in France or abroad, or from public or private research centers.
L'archive ouverte pluridisciplinaire HAL, est destinée au dépôt et à la diffusion de documents scientifiques de niveau recherche, publiés ou non, émanant des établissements d'enseignement et de recherche français ou étrangers, des laboratoires publics ou privés. 
ON STRUCTURAL FINITE ELEMENT MODELING STRATEGIES AND THEIR INFLUENCE ON THE OPTIMIZATION OF FINAL CONSTRUCTABILITY OF REINFORCED CONCRETE STRUCTURES

\author{
Guillaume Hervé-Secourgeon ${ }^{1,}{ }^{*}$, Estelle Hervé-Secourgeon ${ }^{1,2}$, Marina Bottoni1 ${ }^{1}$, \\ François Voldoire ${ }^{1}$, Mihaja Razafimbelo ${ }^{1,2}$, Fabrice Gatuingt ${ }^{2}$, Cécile Oliver- \\ Leblond $^{2}$, Tulio Honorio ${ }^{2}$, Ahmad Kameh ${ }^{3}$, Souheil Habib ${ }^{1}$, Florian Escoffier ${ }^{1}$ \\ ${ }^{1}$ Institute of Mechanical Sciences and Industrial Applications, EDF-CNRS-CEA-ENSTA UMR 9219, and \\ EDF, R\&D Department, Palaiseau, France \\ 2 Université Paris-Saclay, ENS Paris-Saclay, CNRS, UMR 8535 LMT - Laboratoire de Mécanique et \\ Technologie, 91190, Gif-sur-Yvette, France \\ ${ }^{3}$ Ecole des Ponts ParisTech, 77420 Champs-sur-Marne, France
}

${ }^{*}$ Corresponding author: Guillaume Hervé-Secourgeon (guillaume.herve-secourgeon@edf.fr), EDF Lab - Boulevard Gaspard Monge, 91120 Palaiseau, France

ABSTRACT

The design of nuclear civil structures based on rules in European standards makes extensive use of the Finite Element Method (FEM). The size and complexity of the models are continuously increasing. Lately, the post-processing of the FEM results has centered the engineers' contribution on analyzing the reinforcement density produced using automated methods dealing with shell or plate models, which often leads to excessive plate use even in D-regions (discontinuity or disturbance region). This practice is particularly problematic for nuclear structures, which exhibit a large set of massive parts due to radiation protection requirements in many areas such as the reactor pit, the raft, or the 
containment gusset. Furthermore, these substructures are generally not well aligned with thin structural elements (such as slabs and walls) due to heavy equipment, piping, and HVAC (heating, ventilation, and air conditioning) constraints. This is contrary to what should be done to achieve the best engineering design

To address these issues, an overall modeling and post-processing approach is proposed herein. The objective is to enhance the implementation of the finite element model and the post-processing phase to improve the quality of the modeling and reinforcement of B (non-disturbed region) and D regions without significantly impacting the time needed for the design.

A second objective of the proposed methods is to improve the constructability of reinforced concrete nuclear structures. Indeed, the current modeling approach, which often misuses shell elements, often leads to a significant overestimation of the required reinforcement density and consequently complicates the fabrication of the reinforced concrete structures.

To illustrate the approach used here, an example based on a building typical of a nuclear structure is presented. The distinct benefits of both the overall modeling and the reinforcement post-processing are highlighted. This approach exhibits a saving of nearly $25 \%$ on the bending reinforcement sections of the outer walls compared to a practice that doesn't account for the improvements presented in the paper. Moreover, it reduces the maximum values of reinforcement due to bending of a plate by almost $40 \%$ without changing the reinforcement calculation process. It also provides a smoothing method of the reinforcement ratio fringes based on energy conservation. The method is automated and replaces the common, time-consuming practice of averaging the reinforcement ratios for arbitrary defined sets of finite elements.

Keywords: Reinforced Concrete Design, Modeling Strategy, Constructability, Wall-Slab Connections, Strut-and-Tie Model, Optimization, Reinforcement calculation 


\section{Introduction}

Since the introduction of the Finite Element Method (FEM) codes, advanced material and finite element models have been developed to analyze and design concrete structures. In contrast, the modeling and post-processing techniques used by the nuclear industry are evolving slowly. Nevertheless, it is possible to improve the way these structures are designed with a more consistent approach, even without changing the design standards.

Current calculation and post-processing methods based on shell elements lead to local excesses of reinforcement densities (see (Hervé, et al., 2014 (a)) and (Hervé, et al., 2014 (b)). It is quite common for engineers to decrease these peaks by smoothing the reinforcement densities over a set of adjacent finite elements. Since the smoothing methods are not detailed in construction standards, it is usually done using "engineering judgment" or heuristics that lack a robust mechanical basis and are therefore open to discussion. Moreover, this step can be time-consuming. This issue was addressed by (Eleftheriadis, et al., 2018), where smoothing was carried out at the end of the local reinforcement calculation but without challenging the modeling and post-processing.

This paper focuses on enhancing the overall modeling and post-processing approach to improve the quality of the mechanical response by avoiding the use of shell elements in D regions and provides methods to handle D regions properly. These new methods are implemented in a finite element software, reducing the engineering time required to set up the model. This approach considerably decreases the reinforcement ratio in B regions (non-disturbed strain regions), thus reducing the need for smoothing. Furthermore, a mechanically based method is proposed to smooth the reinforcement ratios in these $\mathrm{B}$ regions inspired by existing approaches used to treat $\mathrm{D}$ regions.

The propositions are substantiated using a simple structure with a set of structural features typical of nuclear structures. The appropriate modeling of wall-slab connections through specific elements 
and kinematic relations leads to a consistent reduction in reinforcement, fewer singularities, and a much more realistic stiffness. To address the second objective introduced in the abstract, an academic example is given to illustrate the theoretical background to deal with reinforcement calculation in the multiscale perspective.

\section{Usual engineering practice for the design of reinforced concrete nuclear structures}

The French nuclear practice set up during the last three decades typically consists of the following steps:

- A FEM structural linear analysis (see (RCC-G, 1989), (ETC-C, 2010), (RCC-CW, 2019) which is carried out using principally plate and shell finite elements,

- A standard basis for reinforced concrete buildings (EN1992-1-1:2004, 2004) massively focused on beams and columns or columns and slabs,

- A design flowchart for B regions is organized as follows:

$\circ$ Generation of the reinforcement sections' fringes by post-processing of FEM results based on (Wood, 1968), (Capra \& Maury, 1978) and (Marti, 1991);

- Manual smoothing of the reinforcement sections to avoid the peak values generally related to modeling issues;

- Generation of the reinforcement drawings based on smoothed fringes, considering overlapping and anchorage lengths;

- Outputs of the detailed reinforcement drawings incorporating the rebar arrangements and several details.

If we disregard specific aspects of standards, the overall modeling methods are constrained by certain common architectural aspects. Indeed, the design of nuclear civil structures requires elements with large thickness variability due to constraints related to radiation protection, malicious acts, and heavy 
equipment. Besides that, many thinner walls and slabs are connected to these thicker parts, as shown in Figure 1.

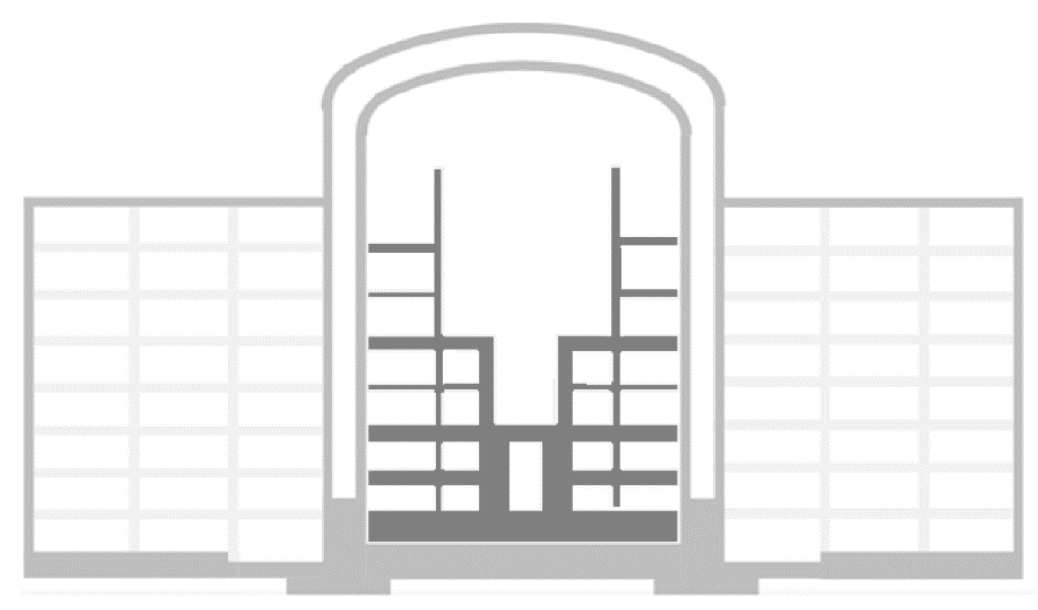

Figure 1: Typical cut of a French EPR based on (Hervé, et al., Comparative study of shell element and brick element models for NPP structures, 2014) for which the concrete thicknesses are schematized to see the association of thick and thin elements.

These thickness variations induce significant variations in stiffness that are not well captured by a model using only plates and shells. The structural scheme of these buildings, braced by shear walls, has a substantial degree of static indeterminacy. It is shown here that the sole use of plate and shell finite elements is not appropriate but shall be coupled to brick elements for every D region, such as connections and massive parts. Nevertheless, if not accompanied by proper post-processing, a change in the modeling of those D regions will not solve constructability issues.

\section{B-Region design enhancement - Toward an automatic smoothing of reinforcement that is mechanically substantiated}

As introduced at the end of the previous section, post-processing needs to be enhanced. Even the most recent papers (Eleftheriadis, et al. , 2018) do not address the non-local issue of reinforcement calculation due to numerical peaks of the quantities of interest (moments and forces). Indeed, they propose algorithms to cope with local reinforcement calculation peaks and smooth them up to the size of the studied structural element (part of a slab or wall). The objective of this section is to propose 
a new fully automated approach. It takes advantage of the field transfer techniques (see (Ibrahimbegovic , et al., 2009)) and conserves the potential energy to consider a complete equivalent set of generalized forces that can be used with classical reinforcement calculation algorithms at a scale larger than the mesh size.

\subsection{Reinforced concrete plate local-global design method}

The underlying assumption related to the Ultimate Limit State design, considering the reinforcement calculation based on (Capra \& Maury, 1978), (Wood, 1968) or the sandwich method (Marti, 1991) at the local finite element scale, is that each element is a potential weak link in the structural design. The calculations are based on linear elastic models considering constant EI values for each load case. This assumption is no longer valid when considering nuclear structures braced by a labyrinth of shear walls and diaphragm slabs with a considerable degree of static indeterminacy.

The first key to the proposed local-global design method of reinforced concrete slabs assumes that the search for a weak link should not be done at the scale of a finite element. Instead, it should be performed at an upper scale consisting of a part of walls or slabs that are hereafter referred to as panels. Therefore, the method focuses on the design of each panel as a whole and not on each finite element within it.

The forces and moments of plates are calculated based on the plate deformation subjected to membrane action, bending, and out-of-plane shear, as shown in Table 1 . These elements are coming from the displacements and rotations of the mid-plane for Kirchhoff-Love plates considering the hypothesis of small strains. 
Table 1: Forces and moments based on displacement and rotations in Kirchhoff-Love plates.

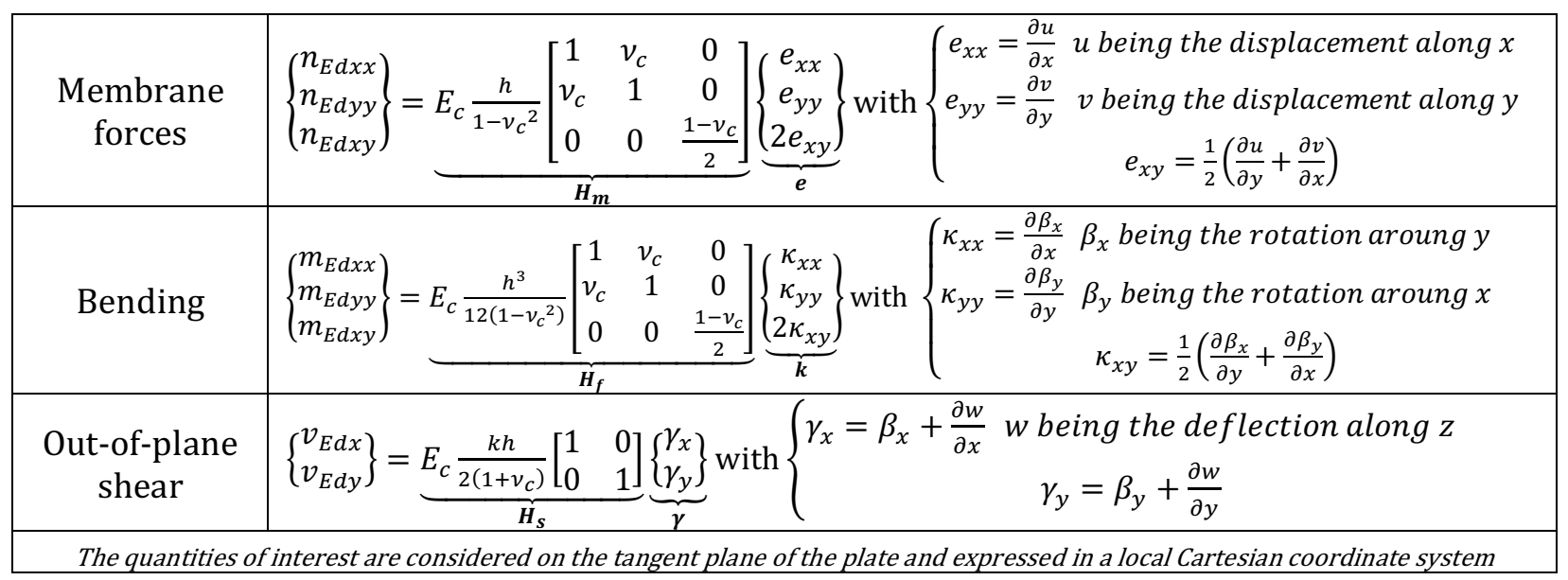

\subsubsection{Automatic identification of homogeneous zones}

The use of panels requires their division into sub-domains by considering out-of-plane bending and shear since those terms can evolve within a wall or a slab. However, the membrane forces are approximately homogeneous within a panel. The typical quantity of interest of these mechanical responses is the vector of rotations at the mid-plane level. Thus, a scalar indicator $\left(i_{\boldsymbol{\beta}}\right.$ in Equation (E. 1)) is proposed here, based on the sum of the square of their divergence. It is proposed here to take into account the local extrema of intensity to generate the seeds of a Voronoi of the panel ( (Voronoï, 1908) ; (Aurenhammer, et al. 2013)). This indicator consists of the quadratic sum of the curvature in the local coordinate system of the plate.

$$
i_{\boldsymbol{\beta}}=\left[\vec{\nabla}\left(\begin{array}{c}
\beta_{x} \\
\beta_{y}
\end{array}\right)\right]^{T}\left[\vec{\nabla}\left(\begin{array}{c}
\beta_{x} \\
\beta_{y}
\end{array}\right)\right]=\left(\frac{\partial \beta_{x}}{\partial x}\right)^{2}+\left(\frac{\partial \beta_{y}}{\partial y}\right)^{2}=\kappa_{x x}{ }^{2}+\kappa_{y y}{ }^{2}
$$

The geometrical singularities of the structural elements are also considered to generate the seeds since those geometrical singularities may not lead to a local extremum for the $i_{\beta}$ indicator. 
The example of a $5 \mathrm{mx} 10 \mathrm{~m}$ plate clamped on two adjacent edges and loaded with a vertical load on the two opposite sides is proposed (see Figure 2) to provide a simple illustration of the method.

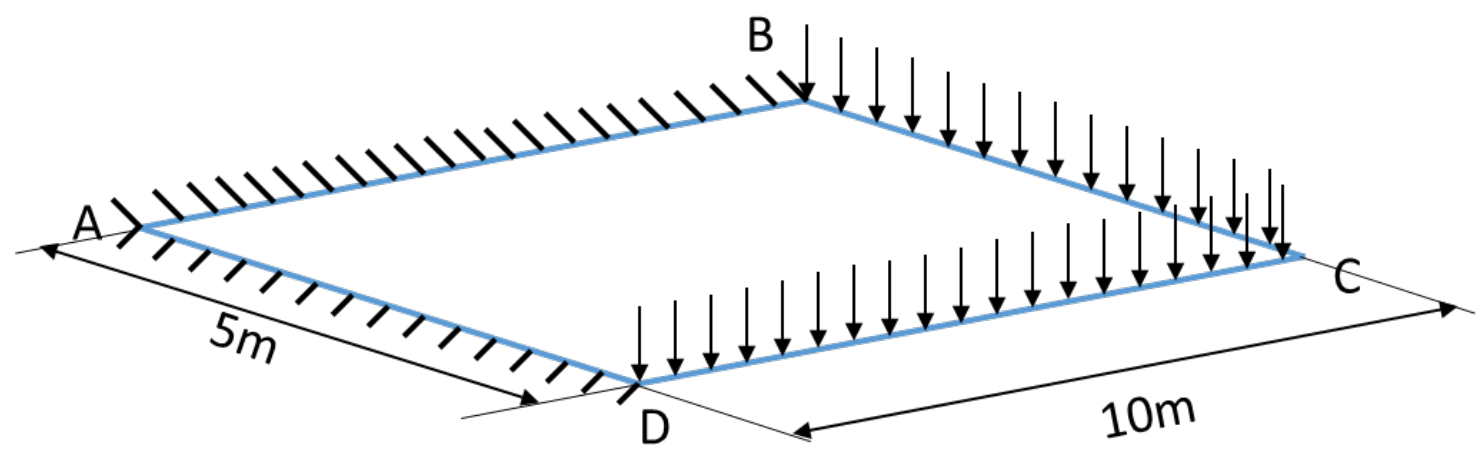

Figure 2: Rectangular slab $(5 \mathrm{~m} \times 10 \mathrm{~m})$ clamped on the upper and left borders

The $i_{\beta}$ indicator is plotted Figure 4 . In this case, its extrema are located at the same place as the four corners' geometrical singularities. This leads to a very simple Voronoi tessellation that divides the slab into four panels, as shown in Figure 3.

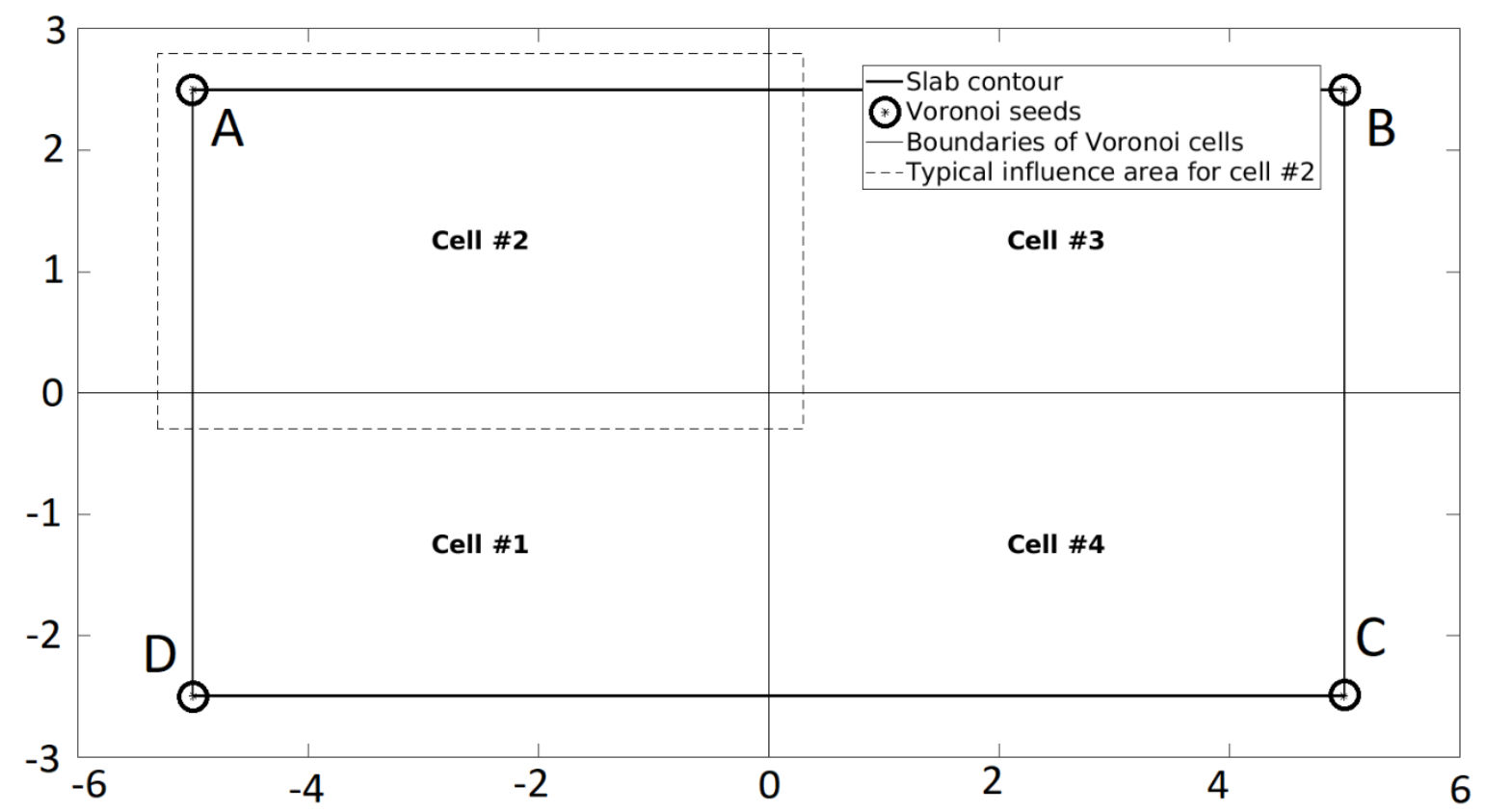

Figure 3: Rectangular slab of Figure 2 figuring out the cells (panels) automatically generated by Voronoi tessellation considering the seeds in Figure 4 


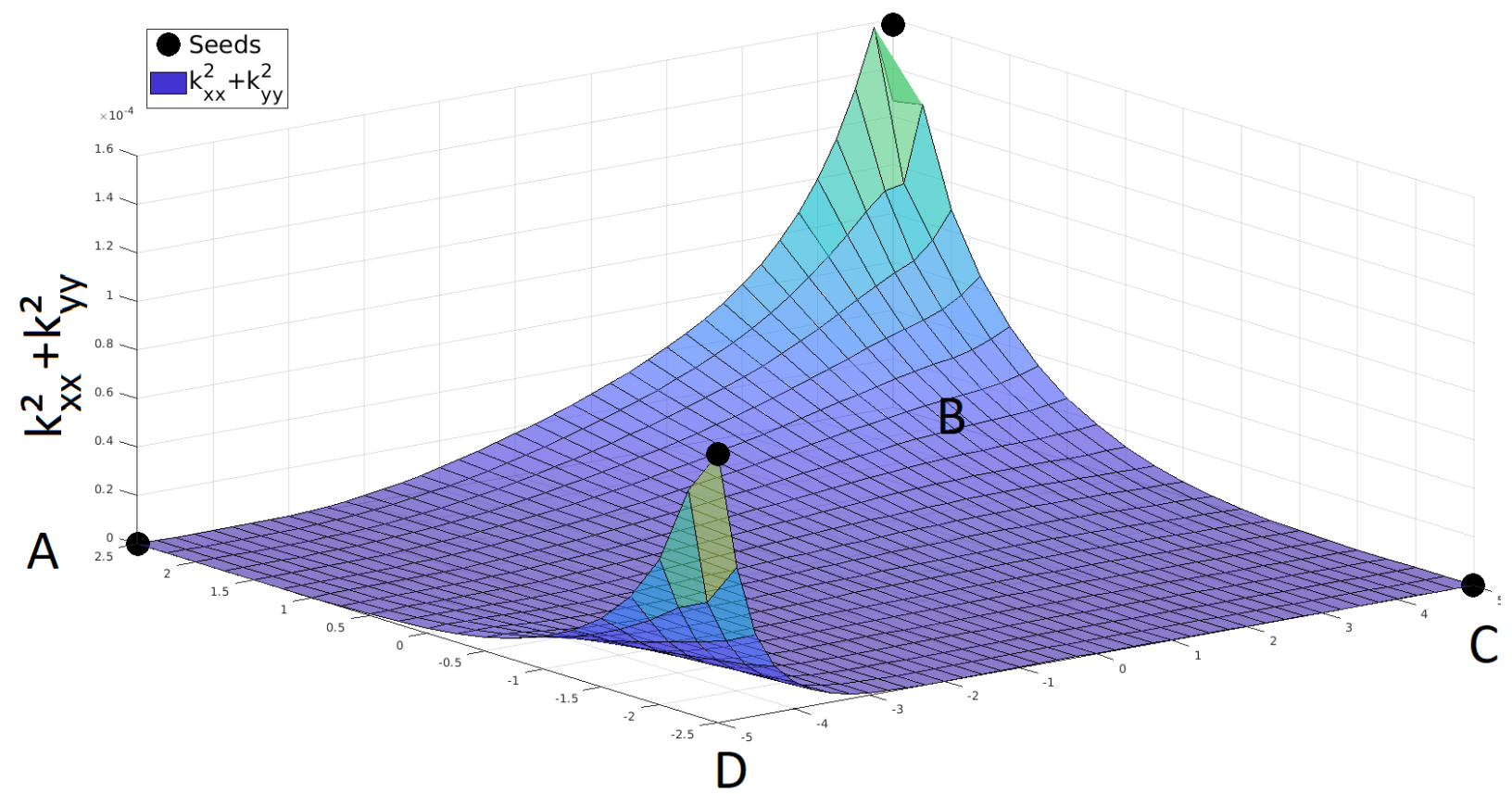

Figure 4: $i_{\beta}$ indicator with the associated seeds for the slab exposed in Figure 2

\subsubsection{Local-global expression of the deformations}

The Voronoi algorithm provides a tessellation of the domain through a set of polygons that are not necessarily rectangles (unlike what is shown in Figure 4, which is a specific case). Therefore, it is considered that for any of the polygons of the Voronoi tessellation, a rectangle that bounds its corners and whose segments are parallel to the global coordinate system. This rectangle is considered as an influence area used to set up the local-global method applied to the deformation vector. The zones of influence extend beyond the area of the polygons by the length of the rebar anchorage. A length of $30 \mathrm{~cm}$ is used, which corresponds to 15 times the diameter of a $20 \mathrm{~mm}$ rebar, according to the (EN1992-1-1:2004, 2004). The homogenization associated with the local-global approach is carried out using a weighted least square regression. This method is directly inspired by (Ibrahimbegovic, et al. 2009). Different weighting functions are introduced depending on the nature of the deformation. These functions are expressed in equation (E. 2) and are plotted in Figure 5, Figure 6 and Figure 7. They were chosen to maximize the value of the out-of-plane curvature in the center of the influence 
and the out-of-plane distortions at its boundaries. This way, the weighting functions presented in Figure 5,Figure 6 and Figure 7 are consistent with the concept of the $i_{\boldsymbol{\beta}}$ indicator.

$$
\left\{\begin{array}{c}
w_{\kappa}(x, y)=\left[\left(\frac{x}{\frac{l_{x}}{2}}\right)^{4}-2\left(\frac{x}{\frac{l_{x}}{2}}\right)^{2}+1\right] \times\left[\left(\frac{y}{\frac{l_{y}}{2}}\right)^{4}-2\left(\frac{y}{\frac{l_{y}}{2}}\right)^{2}+1\right] \text { for the curvatures } \\
w_{\gamma}(x, y)=1-w_{\kappa_{x x, \kappa_{y y}}}(x, y) \text { for the distortion } \\
x \text { and y origins are at the center of the influence area }
\end{array}\right.
$$

The other quantities, such as the in-plane distortion, for in-plane shear force and torsion moment, and the normal extension, for in-plane normal forces, are affected by the same weight set to one.

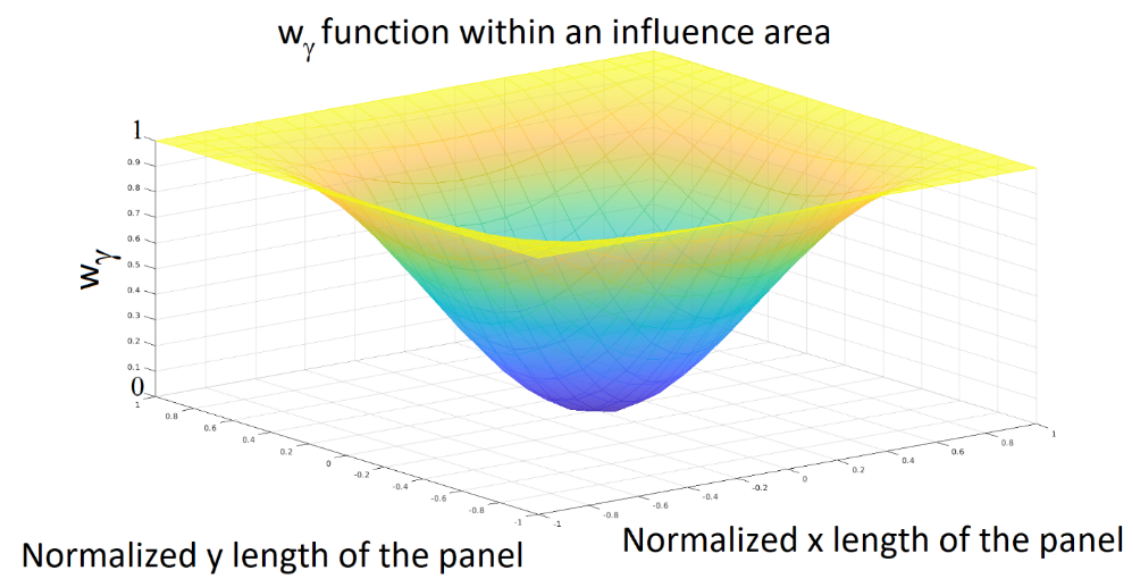

Figure 5: Weighting function associated with the out-of-plane shear $\mathrm{w}_{\kappa}$ function within an influence area

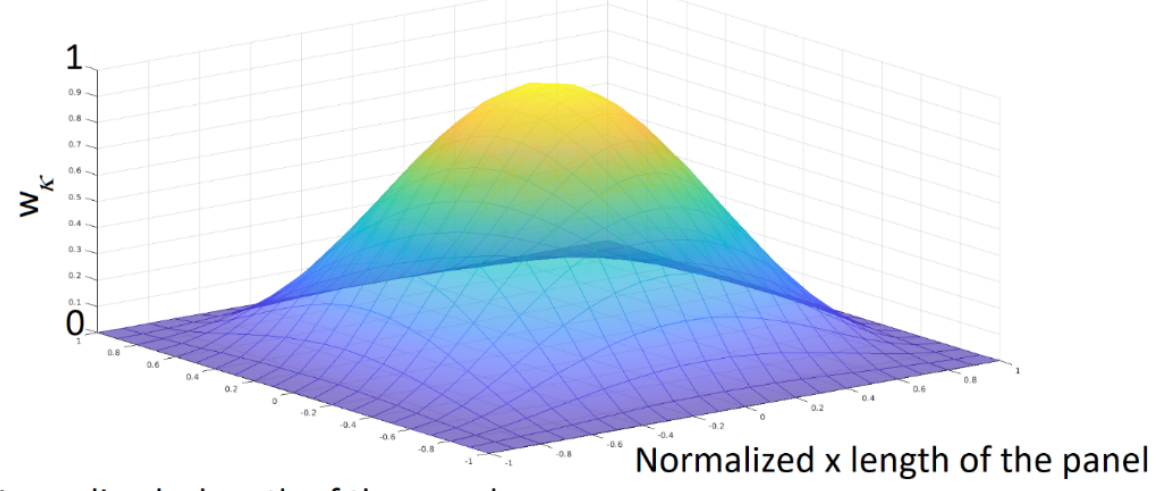

Normalized y length of the panel 
Figure 6: Weighting function associated with the curvature

$\mathrm{w}_{\mathrm{e}}$ and $\mathrm{w}_{\text {distorsion }}$ function within an influence area

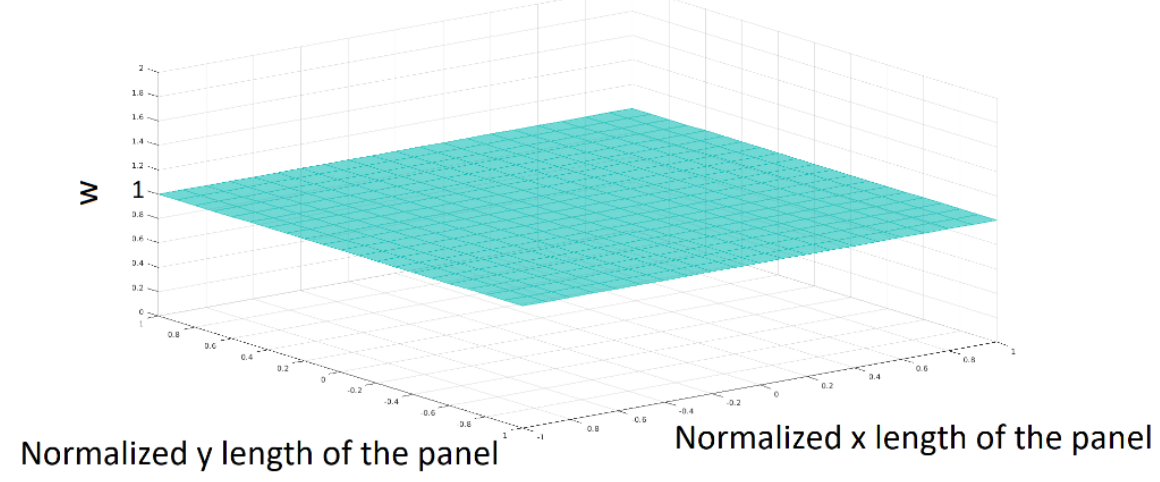

Figure 7: Weighting function associated with the in-plane distortion and extension

Considering each Gauss point $n_{P G}\left(x_{n_{P G}}, y_{n_{P G}}\right)$ of the finite elements located within the influence area whose center of mass is located at $O\left(x_{0}, y_{0}\right)$, the values of the considered weighting function associated to each deformation can be stored in a square matrix as shown in equation (E. 3).

$$
\boldsymbol{W}_{\boldsymbol{k}}=\left(\begin{array}{ccc}
w_{k}\left(x_{1}-x_{0}, y_{1}-y_{0}\right) & \cdots & 0 \\
\vdots & \ddots & \vdots \\
0 & \cdots & w_{k}\left(x_{n_{P G}}-x_{0}, y_{n_{P G}}-y_{0}\right)
\end{array}\right)
$$

The weighted least square minimization of the quantity considered for the homogenization process of $\widetilde{\kappa_{x x}}$ is written in equation (E. 4).

$$
\begin{aligned}
& d=\frac{1}{2}\left(\boldsymbol{\kappa}_{x x}-\widetilde{\boldsymbol{\kappa}_{x x}}\right)^{T} \times \boldsymbol{W}_{\boldsymbol{k}} \times\left(\boldsymbol{\kappa}_{x x}-\widetilde{\boldsymbol{\kappa}_{x x}}\right)
\end{aligned}
$$

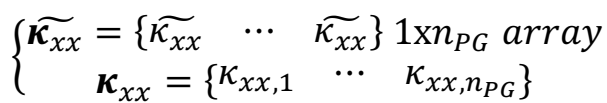

Minimizing the functional $d$ stated in (E. 4) leads to the scalar equivalent value in equation (E. 5):

$$
\left\{\begin{array}{c}
\widetilde{\kappa_{x x}}=\left(\boldsymbol{p} \boldsymbol{W}_{\boldsymbol{\kappa}} \boldsymbol{p}^{T}\right)^{-1} \boldsymbol{p} \boldsymbol{W}_{\boldsymbol{\kappa}} \boldsymbol{\kappa}_{x x} \\
\text { with } \boldsymbol{p}=\left\{\begin{array}{lll}
1 & \cdots & 1
\end{array}\right\}
\end{array}\right.
$$

That is the average value of the quantity of interest weighted by the function $w\left(x_{1}, y_{1}\right)$ in equation (E. 2). For $\widetilde{\kappa_{y y}}, \widetilde{\kappa_{x y}}, \widetilde{\gamma_{x}}, \widetilde{\gamma_{y}}, \widetilde{e_{x x}}, \widetilde{e_{y y}}$, and $\widetilde{e_{x y}}$ the calculation is the same, only the weighting function varies.

\subsubsection{Potential energy conservation}


The homogenized deformations are corrected so that their potential energy equals the sum of the potential energy of any finite element located within the panel of area $S_{\text {panel }}$. This ensures that each considered panel is designed to withstand the appropriate quantity of potential energy that the complete structural response provides. Considering the bending, membrane, and shear potential energy, the homogenized quantities of interest can be calculated as written in equation (E. 6).

$$
\begin{gathered}
\widetilde{W}_{\text {membrane }}=\frac{1}{2} \tilde{\boldsymbol{e}}^{T} \boldsymbol{H}_{\boldsymbol{m}} \tilde{\boldsymbol{e}} \\
\widetilde{W}_{\text {bending }} \frac{1}{2} \widetilde{\boldsymbol{\kappa}}^{T} \boldsymbol{H}_{\boldsymbol{f}} \widetilde{\boldsymbol{\kappa}} \\
\widetilde{W}_{\text {shear }}=\frac{1}{2} \widetilde{\boldsymbol{\gamma}}^{T} \boldsymbol{H}_{\boldsymbol{s}} \widetilde{\boldsymbol{\gamma}}
\end{gathered}
$$

The correction of homogenized potential energy is carried out as presented in equation (E. 7) for the bending case, including the three moments.

$$
\boldsymbol{\kappa}^{*}=\sqrt{\frac{\frac{1}{2} \int_{\text {Spanel }} \boldsymbol{\kappa}^{T} \boldsymbol{H}_{\boldsymbol{f}} \boldsymbol{\kappa} \cdot d S}{\frac{1}{2} \widetilde{\boldsymbol{\kappa}}^{T} \boldsymbol{H}_{\boldsymbol{f}} \widetilde{\boldsymbol{\kappa}} \times S_{\text {panel }}}} \times \widetilde{\boldsymbol{\kappa}}
$$

Based on the corrected homogenized deformation, the forces and moments are calculated as shown in equation (E. 8) for the specific case of bending moments.

$$
\left\{\begin{array}{l}
m_{x x}^{*} \\
m_{y y}^{*} \\
m_{x y}^{*}
\end{array}\right\}=\boldsymbol{H}_{\boldsymbol{f}} \times \boldsymbol{\kappa}^{*}
$$

The expression of each force can be calculated directly using:

$$
\left\{\begin{array}{l}
m_{x x}^{*} \\
m_{y y}^{*} \\
m_{x y}^{*}
\end{array}\right\}=\overbrace{\text { scalar energy corrector }}^{\text {bending stiffness matrix }} \widetilde{\boldsymbol{H}}_{\boldsymbol{f}}^{\sqrt{\frac{\int_{\text {S panel }} \boldsymbol{\kappa}^{T} \boldsymbol{H}_{\boldsymbol{f}} \boldsymbol{\kappa} \cdot d S}{\widetilde{\boldsymbol{\kappa}}^{T} \boldsymbol{H}_{\boldsymbol{f}} \widetilde{\boldsymbol{\kappa}} \times S_{\text {panel }}}}} \times\left\{\begin{array}{c}
\begin{array}{l}
\left(\boldsymbol{p} \boldsymbol{W}_{\boldsymbol{\kappa}} \boldsymbol{p}^{T}\right)^{-1} \boldsymbol{p} \boldsymbol{W}_{\boldsymbol{\kappa}} \boldsymbol{\kappa}_{x x} \\
\left(\boldsymbol{p} \boldsymbol{W}_{\boldsymbol{\kappa}} \boldsymbol{p}^{T}\right)^{-1} \boldsymbol{p} \boldsymbol{W}_{\boldsymbol{\kappa}} \boldsymbol{\kappa}_{y y} \\
\left(\boldsymbol{p} \boldsymbol{W}_{\boldsymbol{e}} \boldsymbol{p}^{T}\right)^{-1} \boldsymbol{p} \boldsymbol{W}_{\boldsymbol{e}} \boldsymbol{\kappa}_{x y}
\end{array} \\
\underbrace{*}_{\text {weighted averaged curvatures }}
\end{array}\right\}
$$




$$
\begin{aligned}
& \left\{\begin{array}{l}
n_{x x}^{*} \\
n_{y y}^{*} \\
n_{x y}^{*}
\end{array}\right\}=\overbrace{\tilde{H}_{\boldsymbol{m}}}^{\text {membrane stiffness matrix }} \underbrace{\sqrt{\frac{\int_{\text {Spanel }} \boldsymbol{e}^{T} \boldsymbol{H}_{\boldsymbol{m}} \boldsymbol{e} . d S}{\tilde{\boldsymbol{e}}^{T} \boldsymbol{H}_{\boldsymbol{m}} \tilde{\boldsymbol{e}} \times S_{\text {panel }}}}}_{\text {scalar energy corrector }} \times\left\{\begin{array}{c}
\begin{array}{c}
\left(\boldsymbol{p} \boldsymbol{W}_{\boldsymbol{e}} \boldsymbol{p}^{T}\right)^{-1} \boldsymbol{p} \boldsymbol{W}_{\boldsymbol{e}} \boldsymbol{n}_{x x} \\
\left(\boldsymbol{p} \boldsymbol{W}_{\boldsymbol{e}} \boldsymbol{p}^{T}\right)^{-1} \boldsymbol{p} \boldsymbol{W}_{\boldsymbol{e}} \boldsymbol{n}_{y y} \\
\left(\boldsymbol{p} \boldsymbol{W}_{\boldsymbol{e}} \boldsymbol{p}^{T}\right)^{-1} \boldsymbol{p} \boldsymbol{W}_{\boldsymbol{e}} \boldsymbol{n}_{x y}
\end{array} \\
\underbrace{}_{\text {weighted averaged strains }}
\end{array}\right\}
\end{aligned}
$$

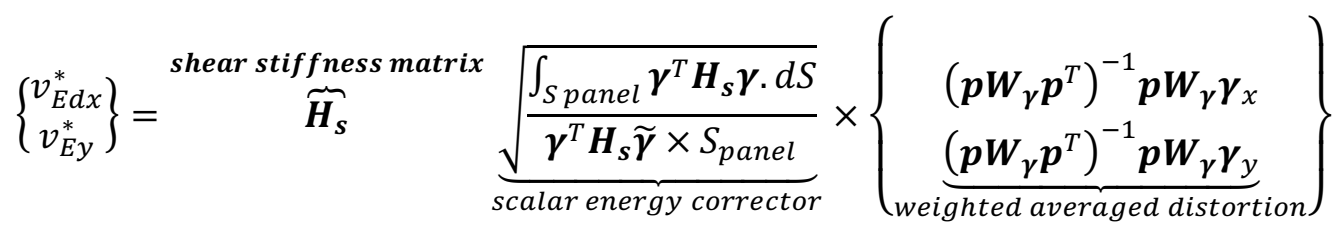

\subsection{Example}

To illustrate the advantages of applying a local-global design method to a reinforced concrete plate, a concrete (C40 concrete strength class, $f_{c k}=40 \mathrm{MPa}$ ) slab with dimensions $10 \mathrm{~m} \times 5 \mathrm{~m} \times 50 \mathrm{~cm}$ is considered. The boundary conditions are the same as shown those in Figure 2. The magnitude of the applied load is $0.25 \mathrm{MN} / \mathrm{m}$. The concrete cover is $5 \mathrm{~cm}$, and the reinforcement is class B500B. In Figure 8, the results at the Ultimate Limit State are compared between local and local-global calculations.

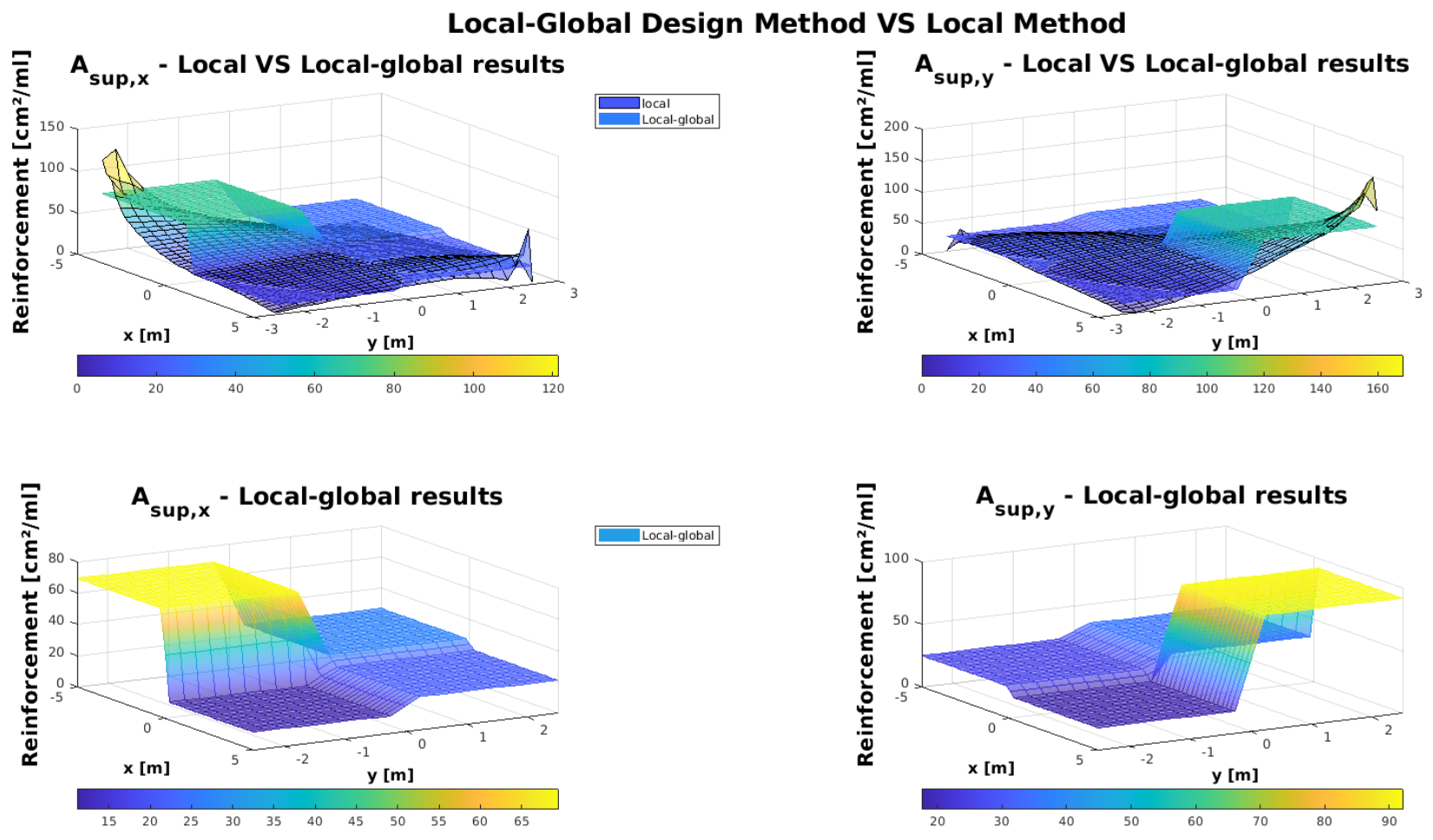

Figure 8: Comparison between local-global results and local results based on section 3.1.3 
Figure 8 exhibits the smoothing of the reinforcement sections over the slab. Figure 9 illustrates the impact of the overall homogenization through the statistical distribution of the reinforcement section for the upper bending reinforcement in direction Y. The design is simplified with only four populations of reinforcement. Those figures show that the updated reinforcement sections, based on the potential energy in each of the panels built with the Voronoi tessellation, equilibrate the overall needs in reinforcement. Moreover, they eliminate local singularities. This result should considerably ease the reinforcement scheduling process. Indeed, smoothing singularities of the raw reinforcement fringes is very time-consuming. Furthermore, the reasoning used to eliminate peaks and smoothing is generally not auditable as it is not thoroughly documented and mainly based on engineering judgement. The proposed methodology avoids this by using arguments based on mechanical assumptions.
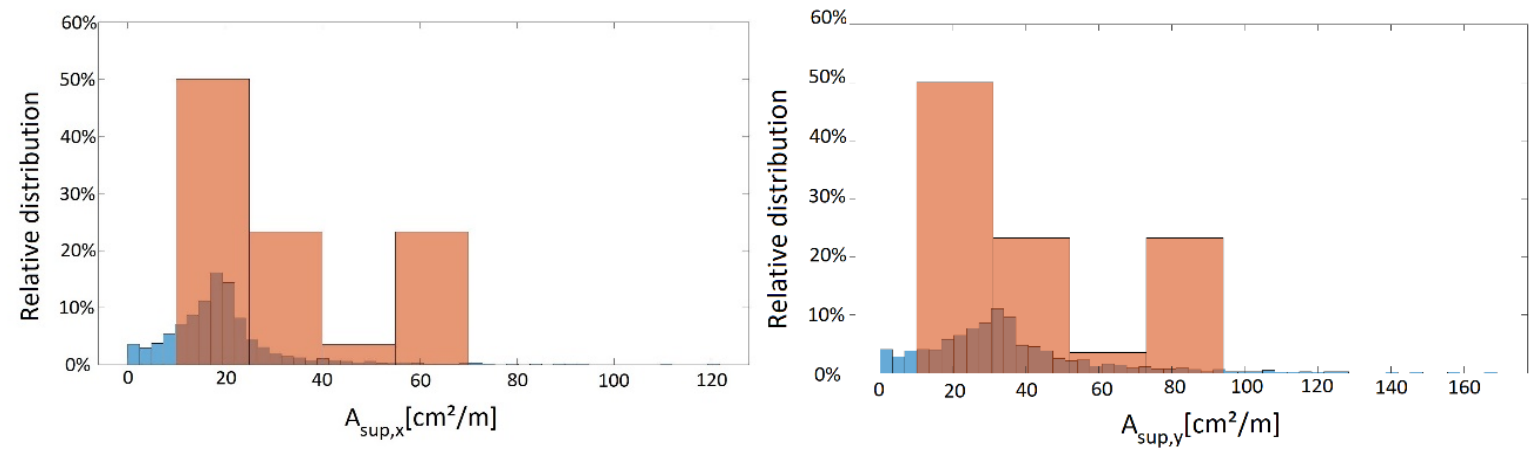

Figure 9: Statistical comparison between local-global results (orange color) and local (blue color) results based on section 0 for the upper layers of bending reinforcement in $X$ and $Y$ directions

This example illustrated the capability of the approach to smooth the reinforcement quantities by considering a rational approach. The result that an experienced engineer could achieve by smoothing the reinforcement quantities by hand might be very similar. Nevertheless, it should be highlighted that the proposed approach is more reliable because it comes from direct exploitation of the calculation results without interpretation. 


\section{D-Region design - Specific case of the massive parts}

The design of D regions (discontinuity or disturbance region) shall be carried out with the strut-andtie method (see (El-Metwally \& Chen, 2018)). Existing approaches are reviewed and divided into three different families to meet the industry's need for automation:

- Discrete topology optimization: This approach consists of the optimization of an equivalent reinforced concrete lattice made of trusses based on the minor principal stress flow path (Mendoza-Chavez, 2018) so that the ground structure (Sotiropoulos \& Lagaros, 2020) is reduced to its smallest size and very consistent with the strut orientations, as recommended in the usual practice (El-Metwally \& Chen, 2018).

- Continuum topology optimization: The minimum amount of material is determined by considering evolutionary or cost function optimization ((Almeida, et al., 2013), (Gayonr et al., 2013, (Liang \& Xie, 2000), (Muttoni, et al. 2015)). The final result requires post-processing, especially for the bonding nodes at the junctions between the struts and the ties. The size and orientation of struts and ties must be obtained based on the final results.

- Bi-material continuum mechanics optimization: this method is an evolution of the topology optimization method described before. In this case, two media with different constitutive equations are superimposed in each finite element (Jewett \& Carstensen, 2019). An optimization algorithm (Sigmund, 2001) or (Bendsoe \& Sigmund, 2003) is applied. The reinforcement can initially be oriented following engineering constraints. The concrete bond in the nodes at the junction between strut and tie, when appropriately modeled, can be used to check nodes' resistances. 
Regardless of the approach considered, it is necessary to perform the analysis for each load combination. Therefore, the engineer must compare the results to identify the rebar arrangement that satisfies the entire set of load combinations.

\section{B-D connection design enhancement - Wall-slab connection case}

There are several types of D regions, and then their connection to the surrounding B regions can vary. In this paper, the specific case of the wall-slab connection is studied. A simple approach based on kinematic operators between plate elements and eight nodes prismatic elements is presented (HervéSecourgeon, Ph.D. Thesis, 2020). For the other general cases, the Arlequin method can be considered, (e.g. (Ben Dhia, 1998) and (Qiao, Yang, Chen, \& Zhang, 2011)).

\subsection{Impact of inappropriate modeling of D Regions of the wall-slab connections}

Among all the possible singularity locations, the peaks in reinforcement density generally occur connection zones. These peaks often drive the reinforcement section choice in nuclear structures, and local peaks often require manual smoothing to avoid excessive reinforcement. In one of the most current European modeling practices of civil work design offices, walls and slabs are represented by plate elements connected perfectly to each other at the structural connection axis. As seen in Figure 11 , the connection is shifted by the thickness of the supporting structural element. An important approximation is made by considering that the concrete part included in the connection volume is only as stiff as the slab or wall when it should necessarily be stiffer. Considering the plate theory as valid in these areas is neither legitimate nor realistic.

To address the error order of magnitude of this modeling strategy, it is also necessary to evaluate the impact of the application of distributed loads to the entire span of a structural element. The results obtained when the distributed loads are applied on the slab only between the inner parts of the walls, rather than up to their mid-plane, should be considered when computing reinforcement demand. 
Due to these modeling practices, the theoretical case of a beam embedded at its two ends is considered to characterize the error quantitatively for static and seismic responses that are computed using the response-spectrum method, as shown in Figure 10. Two different types of loads are considered: a distributed load $p$ or a concentrated load $F$.

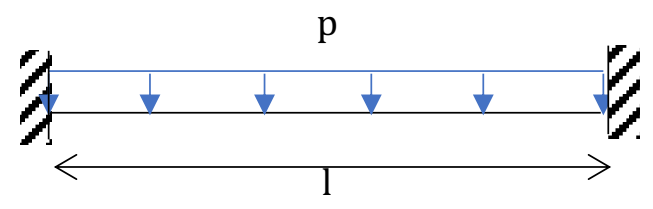

Case \#1

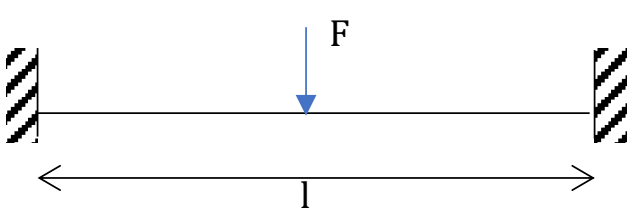

Case \#2

Figure 10: Theoretical examples of embedded beams considering two types of loads

The first natural flexion mode of an Euler-Bernoulli beam clamped at its two ends, and whose accelerated mass is $m=p / g$ is given in Equation (E. 13) considering its modal shape give in Equation (E. 12).

$$
\begin{gathered}
w(x)=-1.01781\left(\cos \left(\frac{4.73}{l} x\right)-\cosh \left(\frac{4.73}{l} x\right)\right)+\left(\sin \left(\frac{4.73}{l} x\right)-\sinh \left(\frac{4.73}{l} x\right)\right) \\
f=\frac{\omega}{2 \pi} \sqrt{g \frac{\int_{0}^{l} w(x) \cdot d x}{\int_{0}^{l} w(x)^{2} \cdot d x}} \simeq \frac{1}{2 \pi} \sqrt{\frac{E I}{m}} \cdot \frac{22,4}{l^{2}} \propto \frac{1}{l^{2}}
\end{gathered}
$$

Its effective mass is given in (E. 14) considering the Rayleigh-Ritz method:

$$
m_{e f f}=\frac{\left(\int_{0}^{l} m \cdot w(x) \cdot 1 \cdot d x\right)^{2}}{\int_{0}^{l} m \cdot w^{2}(x) d x} \simeq 0.69 m l \propto l
$$

A participation factor expression defined in Equation (E. 15) :

$$
p_{k}=-\frac{\int_{0}^{l} m \cdot w(x) \cdot 1 \cdot d x}{\int_{0}^{l} m \cdot w^{2}(x) d x} \simeq 0.81
$$

The maximum displacement at the mid-span is given by Equation (E. 16). It depends on the spectral displacement $S_{d}(f)$. It is thus also the case of the generalized elastic forces and moments since they are directly proportional to $w_{\text {modal }}\left(\frac{l}{2}, f\right)$. 


$$
w_{\text {modal }}\left(\frac{l}{2}, f\right)=w\left(\frac{l}{2}\right) \cdot p_{k} \cdot S_{d}(f)
$$

Therefore, the mid-span response indirectly depends on the span given the expression of the modal frequency, as shown in Equation (E. 17).

$$
w_{\text {modal }}\left(\frac{l}{2}, f\right) \simeq 1.31 . S_{d}\left(\frac{1}{2 \pi} \sqrt{\frac{E I}{m}} \cdot \frac{22,4}{l^{2}}\right)
$$

It is crucial to remember that FEM codes estimate the modal generalized forces based on the modal displacement. This work assesses the impact of not taking the clear span into account, which is quite different.

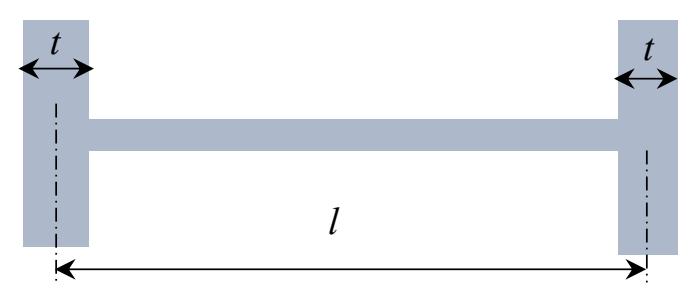

Figure 11: Reference example using center-to-center span, $l$, and clear span, $l-t$

Based on Figure 11, $\rho$ is defined in Equation (E. 18) as the ratio between the average thickness of the columns at the ends of the beam and the span between the mid-axis of the column.

$$
\rho=\frac{t}{l}
$$

Considering this ratio, the Equation (E. 17) and the well-known expressions of the maximum deflection and moment of the cases in Figure 10, the respective errors are expressed and summed up in Table 2. 
Table 2: Modeling error on different quantities for the examples in Figure 10.

\begin{tabular}{|l|c|c|}
\hline Quantities of interest & \#1 - Distributed load - Error & \# 2 - Concentrated load - Error \\
\hline Moment $M$ & $\frac{1}{(1-\rho)^{2}}-1$ & $\frac{1}{(1-\rho)}-1$ \\
\hline Deflection $w$ & $\frac{1}{(1-\rho)^{4}}-1$ & $\frac{1}{(1-\rho)^{3}}-1$ \\
\hline First natural frequency & \multicolumn{2}{|c|}{$(1-\rho)^{2}-1$} \\
\hline
\end{tabular}

As $\rho$ is between 0 and 1 , it is noted that inappropriate modeling leads to an overestimation of the moments and deflections. However, it leads to an underestimation of the natural frequency. In the case of the response-spectrum method, the errors on deflection and natural frequency are not negligible for the Accidental Ultimate Limit State (see (EN1992-1-1:2004, 2004) and (RCC-CW, 2019)) combination involving earthquakes shaking effects. Indeed, modal forces that are proportional to modal displacements are recombined.

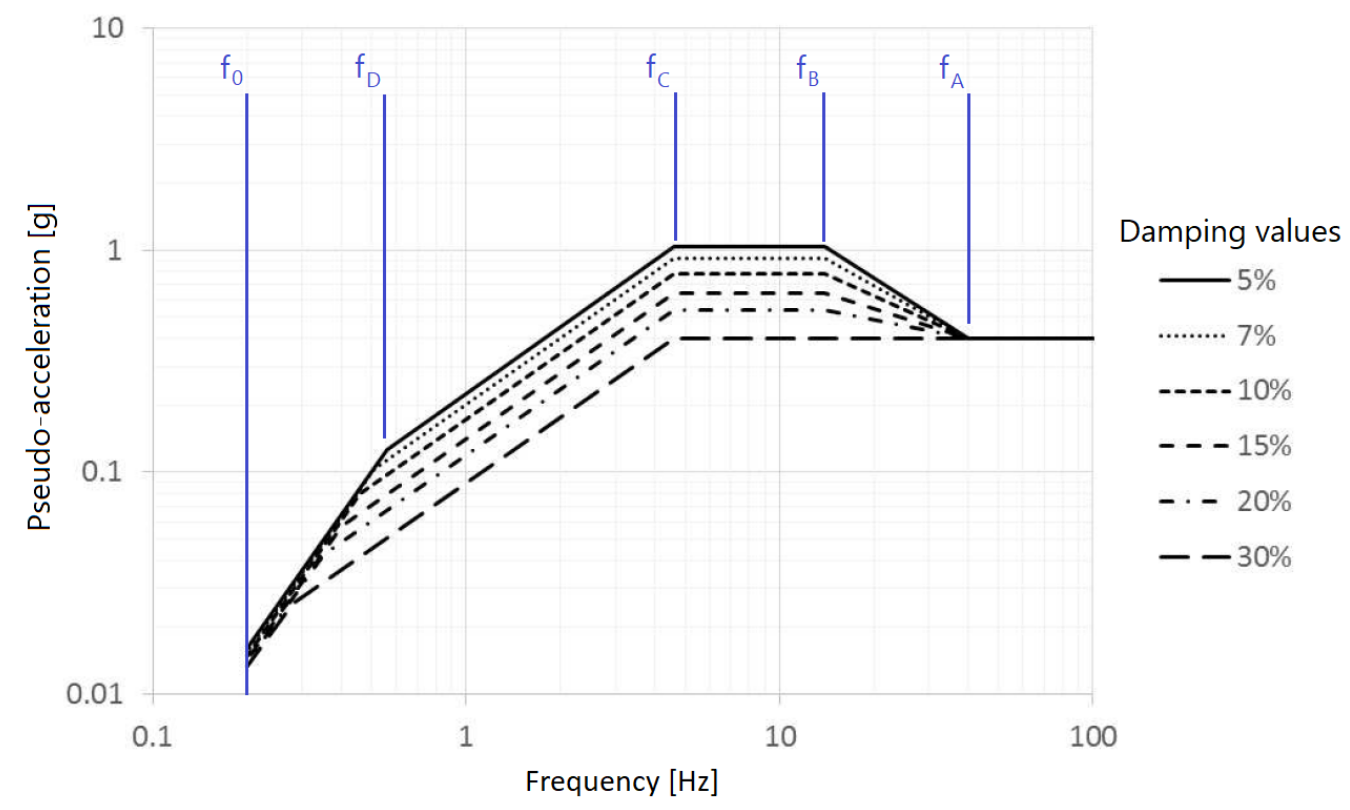

Figure 12: European Utility Requirement acceleration spectrum - Horizontal direction - Scaled at $0.4 \mathrm{~g}$ adapted from (RCC-CW, 2019) 
In Table 3 the example of the European Utility Requirement site spectrum is considered, which is split into five frequency domains. This spectrum is defined for horizontal direction and scaled by $2 / 3$ for vertical shaking.

Table 3: Modeling error on the deflection and the dynamic forces $(c \approx 1,661)$ - Frequencies are illustrated in Figure 12

\begin{tabular}{|c|c|c|}
\hline $\begin{array}{l}\text { Frequency } \\
\text { domain of } \\
f\end{array}$ & Proportionality of the spectral displacement $S_{d}(f)$ & $\begin{array}{l}\text { Error on the deflection } \\
\text { and the dynamic forces }\end{array}$ \\
\hline$\left[f_{0} ; f_{D}\right]$ & Constant displacement: $D_{\max }$ & No impact \\
\hline$\left[f_{D} ; f_{C}\right]$ & Constant velocity: $\frac{V_{\max }}{2 \pi f} \propto l^{2}$ & $\frac{1}{(1-\rho)^{2}}-1$ \\
\hline$\left[f_{C} ; f_{B}\right]$ & Constant acceleration: $\frac{A_{\max }}{4 \pi^{2} f^{2}} \propto l^{4}$ & $\frac{1}{(1-\rho)^{4}}-1$ \\
\hline$\left[f_{B} ; f_{A}\right]$ & $\frac{1}{4 \pi^{2} f^{2}} \cdot 10^{\frac{\log \frac{Z P A}{A_{\max }}}{\log \frac{f_{A}}{f_{B}}} \log \frac{f}{f_{B}}+\log A_{\max }} \propto \frac{1}{f^{2+c \cdot \log \frac{Z P A}{A_{\max }}}} \propto l^{4+2 . c \cdot \log \frac{Z P A}{A_{\max }}}$ & $\frac{1}{(1-\rho)^{4+2 . c . l o g} \frac{Z P A}{A_{\max }}}-1$ \\
\hline$\left[f_{A} ; \infty\right]$ & Constant Zero Period Acceleration: $\frac{Z P A}{4 \pi^{2} f^{2}} \propto l^{4}$ & $\frac{1}{(1-\rho)^{4}}-1$ \\
\hline
\end{tabular}

As stated before, the peaks of reinforcement densities are observed in the connection regions between different slabs and walls. Some finite elements at the extremities of the plates are located within these connections due to the thicknesses of the structural elements. The reinforcement of the connections is set up by continuity of the reinforcement of the connected slabs and walls when the preliminary sketches of reinforcement are done, taking into account the mandatory rebar arrangements based on the applicable standard (RCC-CW, 2019). This is a source of overestimated reinforcement demand, as the reinforcement density at this location is driven by the value of the connected plates in the vicinity impacted by inappropriate modeling of the connection. Modeling the clear span should be carried out to account for suitable application loads, the appropriate rigidity, and avoid singularities. A modeling strategy is hereafter proposed to follow this recommendation. 


\subsection{Hybrid modeling method to improve B-D connection at the wall-slab junctions}

To improve the finite element models in the areas of wall-slab connections, or wall-wall connections, and to reduce the modeling errors detailed in section 5.1, changes to the modeling strategy for these areas are proposed.

To define this strategy, the kinematics and rigidity of the connection zone were addressed. The onehundred-percent plate model usually used in engineering is constrained by the fact that the structural elements (wall, slab) are supposed to be extended to the axis of the connection by plate elements or shells of flexibility equal to that of the structural element, generally loaded identically to the floor (mass, distributed loads), as detailed in section 5.1.

In this paper, a model is proposed that offers a significant improvement in the representation of the kinematics and stiffness of the connection zone, while remaining compatible with the use of plate or shell finite elements for the representation of structural elements such as walls or floors. To this aim, a specific connection element, which represents the homogenized behavior of the connection, is introduced within the shared volume between connected walls and slabs as presented in Figure 13.

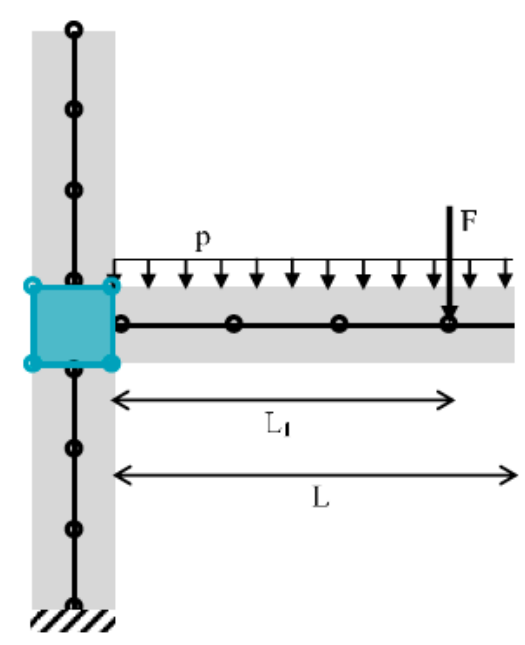

Figure 13: Principle of a wall-slab connection with the proposed model 
The study of the connection kinematics on a reference model, made up entirely of brick elements and subjected successively to out-of-plane displacements of the floor and walls and in-plane displacements of the floor, has been intensively carried out in (Hervé-Secourgeon, et al., 2019). It led to the identification of several main deformation modes in the plane perpendicular to the connection's axis listed in Table 4. The proposed method provides a modeling methodology that is easily automatized. It provides flexible junctions for instead of the rigid end offset method that has been well understood for frame structures.

Table 4: Main deformation modes (in a plane perpendicular to the axis of the connection)

\begin{tabular}{|c|c|c|c|}
\hline Mode & $\begin{array}{c}\text { Shear } \\
(1)\end{array}$ & $\begin{array}{c}\text { Horizontal and vertical } \\
\text { bending } \\
\text { (2 et 3) }\end{array}$ & $\begin{array}{c}\text { Horizontal and vertical } \\
\text { dilation } \\
\text { (4 et 5) }\end{array}$ \\
\hline Sketch & S & \\
\hline
\end{tabular}

To these five modes of deformation, along the connection axis, the three rigid body motion modes must be added: two modes of translation and the mode of rotation around the connection axis, as discussed in (Hervé-Secourgeon, et al., 2019).

Apart from the tensile / compression deformation modes, whose contribution to the structure's deformations is very small, the deformation modes correspond to those of a rectangular, linear, firstorder, finite element, with the faces of the connection remaining mainly plane. In three dimensions, these observations remain true.

Therefore, it is proposed to model the connection at the scale of the building by a first-oder, isoparametric, finite hexahedral brick element. This element is representative of the homogenized behavior of the connection within the shared volume between the connected walls and slabs. To transfer both translations and rotations between these elements and the connected plates, linear kinematic relations are considered so that the average translations and rotations are transferred, 
based on the hypothesis that the faces of the connections remain plane. The Kirchhoff-Love hypotheses on the section deformations are satisfied at the border between the B and D zones by the kinematic relations written, added to the equations governing the elastic connection hexahedral element.

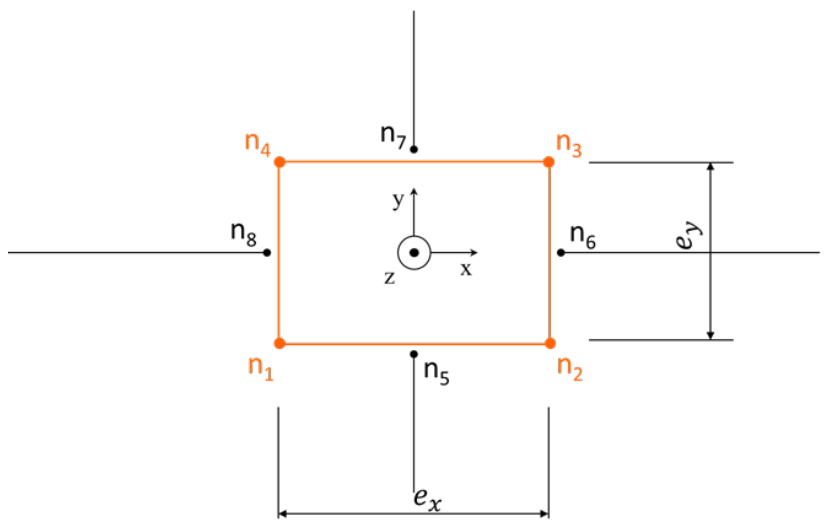

Figure 14: Node numbering of the brick connection element in the plane perpendicular to the connection axis

It is noted in Figure 13 that the nodes in the local coordinate system of the connection that $n_{1}, n_{2}, n_{3}$, $n_{4}$, belong to the connection and $n_{5}, n_{7}, n_{6}, n_{8}$ belong respectively to the connected walls and floors. The corresponding kinematic relations are written as to ensure continuity between the structural element and the connection, as detailed in Equation (E. 19).

$$
\left\{\begin{aligned}
u_{x_{n_{5}}} & =\frac{u_{x_{n_{1}}}+u_{x_{n_{2}}}}{2} \\
u_{y_{n_{5}}} & =\frac{u_{y_{n_{1}}}+u_{y_{n_{2}}}}{2} \\
u_{z_{n_{5}}} & =\frac{u_{z_{n_{1}}}+u_{z_{n_{2}}}}{2} \\
\theta_{x_{n_{5}}} \text { and } \theta_{y_{n_{5}}} & \text { are not constrained } \\
\theta_{z_{n_{5}}} & =\frac{u_{y_{n_{2}}}-u_{y_{n_{1}}}}{e_{x}}
\end{aligned}\right.
$$

These kinematic relations are used to enrich the matrix of global rigidity through dualization using Lagrange multipliers corresponding to the generalized forces connecting the degrees of freedom of the plates / shells representing the floors and walls with the degrees of freedom of the brick elements. This model has been implemented in EDF's in-house FEM Code code_aster (code_aster, 2020). 
The validation of this elastic model for wall-slab connections has been carried out through a systematic comparison between the proposed methodology, the usual practice based only on plates and a reference brick element model validated by means of physical experiments on large scale models. This validation is demonstrated in (Hervé-Secourgeon, Ph.D. Thesis, 2020) and (HervéSecourgeon, et al., 2019) and summarized in Figure 15, Figure 16 and Table 4. One can see that the proposed method is almost systematically closer (for 5 cases out of 7 ) to the reference than the current practice in terms of the macroscopic stiffness measurement (ratio between the applied force or moment and the displacement or rotation observed at the application point of the force). Moreover, the error does not exceed 5\% when the connection is modeled with brick elements, while it can exceed $10 \%$ if only plates are used.

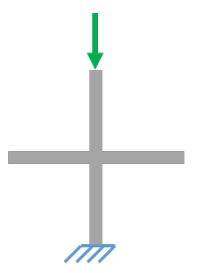

V2

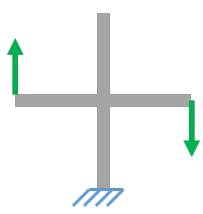

V4

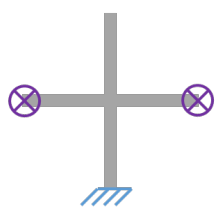

$\mathrm{H} 6$

Cross sections of walls and slabs reference models

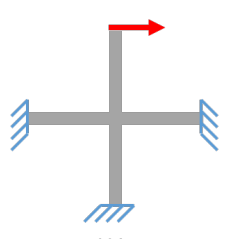

$\mathrm{H} 1$

$\longrightarrow$ Horizontal force applied along the edge

Vertical force applied along the edge

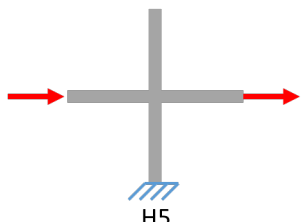

H5

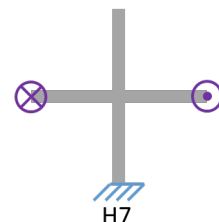

$\mathrm{H} 7$

Q Horizontal negative out-of-plane force applied along the edge

- Horizontal positive out-of-plane force applied along the edge

Figure 15: Reference cases based on (Hervé-Secourgeon, Ph.D. Thesis, 2020) involving three wall thicknesses from $30 \mathrm{~cm}$ to $80 \mathrm{~cm}$ and three slab thicknesses from $10 \mathrm{~cm}$ to $60 \mathrm{~cm}$ 


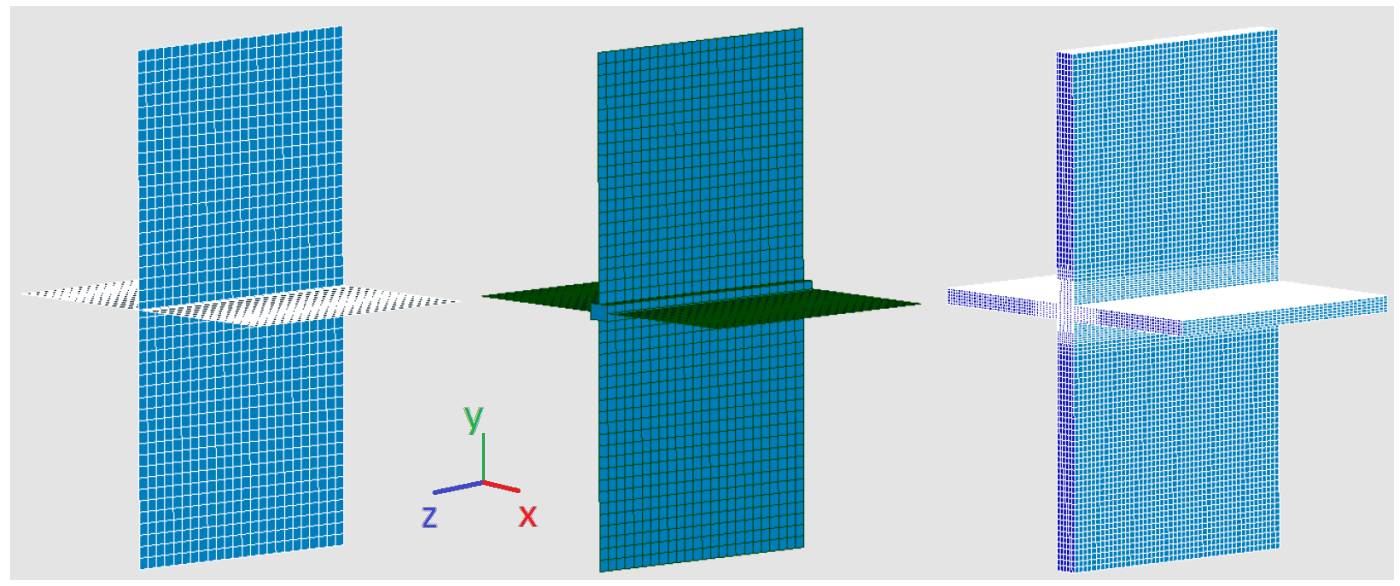

(a)

(b)

(c)

Figure 16: Reference meshes - Full plate model (a) / Hybrid model (b) / Full brick model (c) based on (HervéSecourgeon, Ph.D. Thesis, 2020)

Table 5: Summary of the validation test results (in \%) in (Hervé-Secourgeon, et al., 2019)

\begin{tabular}{|c|c|c|c|c|c|c|c|c|}
\hline \multicolumn{2}{|c|}{$\begin{array}{c}\text { Macroscopic stiffness } \\
\text { comparison (negative value: } \\
\text { stiffness smaller than } \\
\text { reference model) }\end{array}$} & H1 & V2 & V3 & V4 & H5 & H6 & H7 \\
\hline \multirow{2}{*}{$\begin{array}{l}\text { Proposed } \\
\text { model VS } \\
\text { reference full } \\
\text { brick model }\end{array}$} & $\begin{array}{l}\text { Median } \\
\text { value of the } \\
\text { relative } \\
\text { difference } \\
\end{array}$ & 4 & -1 & 2 & 5 & 5 & 1 & -2 \\
\hline & $\begin{array}{l}\text { Standard } \\
\text { deviation of } \\
\text { the relative } \\
\text { difference } \\
\end{array}$ & 2 & 1 & 1 & 2 & 2 & 0 & 2 \\
\hline \multirow{2}{*}{$\begin{array}{l}\text { Plate model VS } \\
\text { reference full } \\
\text { brick model }\end{array}$} & $\begin{array}{l}\text { Median } \\
\text { value of the } \\
\text { relative } \\
\text { difference } \\
\end{array}$ & -4 & -1 & -10 & -6 & -3 & -2 & -2 \\
\hline & $\begin{array}{l}\text { Standard } \\
\text { deviation of } \\
\text { the relative } \\
\text { difference }\end{array}$ & 4 & 1 & 10 & 9 & 4 & 2 & 2 \\
\hline
\end{tabular}




\subsection{Example on a structure typical of a nuclear building}

A proof of concept has been carried out to evaluate the impact of the proposed modeling on seismic reinforcement design. A simple structure was defined to ease visualization of the structural response. It integrates some characteristics still up to date in nuclear buildings, considerable differences in thickness from one structural element to another, discontinuity in walls (that is sometimes unavoidable due to installation constraints), and a thick raft.

The structure is a $10.6 \mathrm{~m} \times 6.6 \mathrm{~m} \times 25 \mathrm{~m} 5$-story building. Each story has an average height of $5 \mathrm{~m}$, with a $1.5 \mathrm{~m}$ thick raft and walls. The thickness of the floors varies between $0.2 \mathrm{~m}$ and $0.6 \mathrm{~m}$.

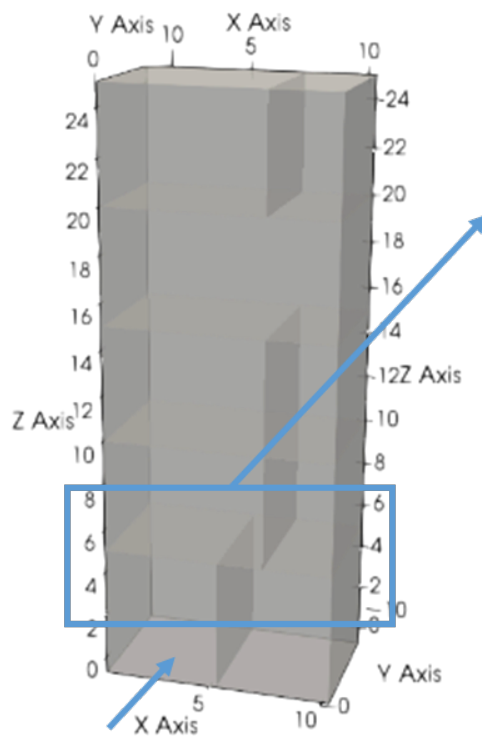

Raft: plates

Soil: springs mat
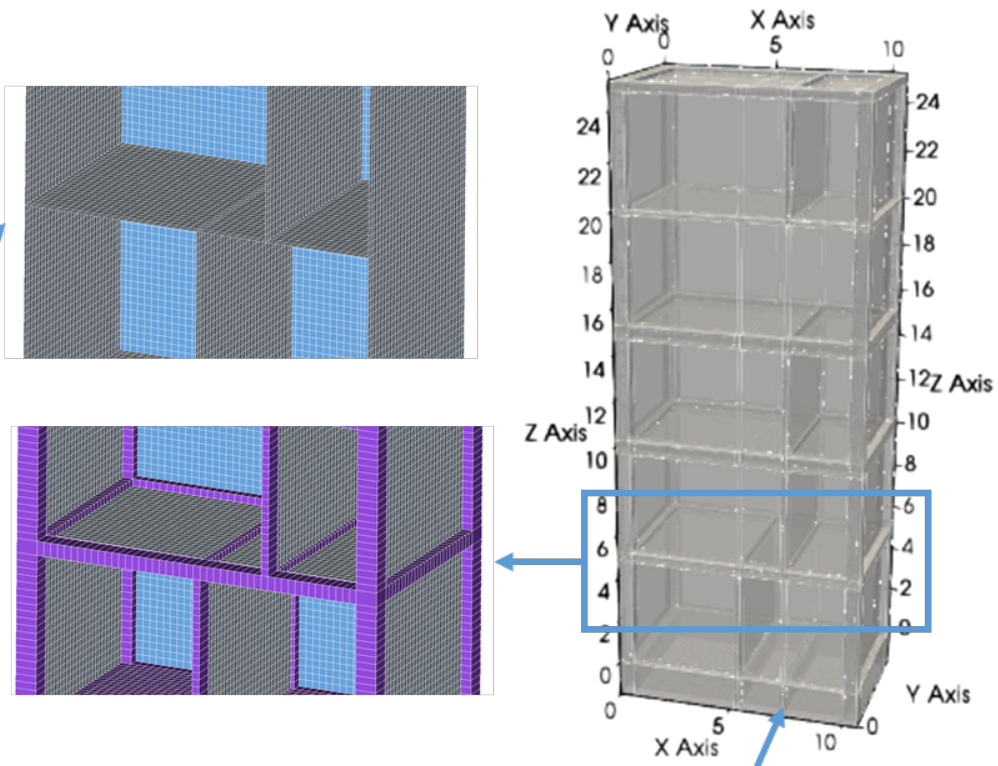

Raft: bricks

Soil: springs mat

(b)

Figure 17: 3D views of both models illustrating different approaches for the FEM models - (a) usual practice (plates only) / (b) hybrid model (bricks, plates and wall slab connections) 
Two models of this building, illustrated in Figure 17, were built:

- A reference model using plates,

- A hybrid model: the raft, the wall-slab and wall-wall connections modeled using brick elements, brick-plate connection were implemented using kinematic relations based on Lagrange multipliers.

A hard soil was considered: HA soil per the European Utilities Requirements, with a shear modulus $G=6 G P a$, a Poisson's ratio equal to 0.3 , and a shear wave velocity $V_{s}=1550 \mathrm{~m} / \mathrm{s}$. A spring mat represents it in translation in three directions. The soil impedance curves were calculated following the simplified Deleuze method (Deleuze, 1967) that provides in that specific case the same results as (Gazetas, 1991).

The permanent and variable loads on the floors are between $10 \mathrm{kN} / \mathrm{m}^{2}$ and $20 \mathrm{kN} / \mathrm{m}^{2}$. The earthquake is represented by a broad-band hard ground EUR spectrum, scaled to a ZPA value of $0.4 \mathrm{~g}$ for the horizontal direction. The spectrum is scaled by $2 / 3$ vertical shaking.

A comparison of the deformed shape of the structure of section 5.1 loaded by gravity loads shows similar shapes but with reduced deformations at mid-span for the hybrid model. As the hybrid models allow for the consideration of the clear span of elements, the deflections at mid-span computed with the hybrid model are reduced. It should be noticed that the span of the walls and slabs considered with the hybrid model for the considered building, is reduced by $6 \%$ to $16 \%$.

The dynamic behavior of the two buildings, with a clamped base, is very similar with a negligible impact on the overall modal shapes and frequencies. Nevertheless, the impact on the local modes (bending modes of the individual walls or slabs for instance) is more significant, with slightly higher frequencies computed with the hybrid model. Two sources can be identified that account for these differences:

- the mass set in motion by the earthquake is reduced by $6 \%$ in the hybrid model because the mass in the connections' area is not double counted, and the surface loads are limited to the 
clear dimensions;

- the stiffness of the structural elements (walls, slabs), directly linked to their spans as shown in section 5.1, is increased in the hybrid models.

When accounting for the soil-structure interaction through a spring mat, the difference between the two models is slightly more significant. There is up to $1 \mathrm{~Hz}$ difference in the natural frequencies of the global modes. This is due to the impact on the flexibility of the raft when using brick elements in hybrid model. The modal behavior remains relatively similar between the two models.

Figure 18 shows - with an identical color scale - the Y-direction reinforcement demand (in the vertical direction for the walls, in the Y-axis direction for the floors), for the lower faces. The reinforcement calculation follows (Capra \& Maury, 1978).
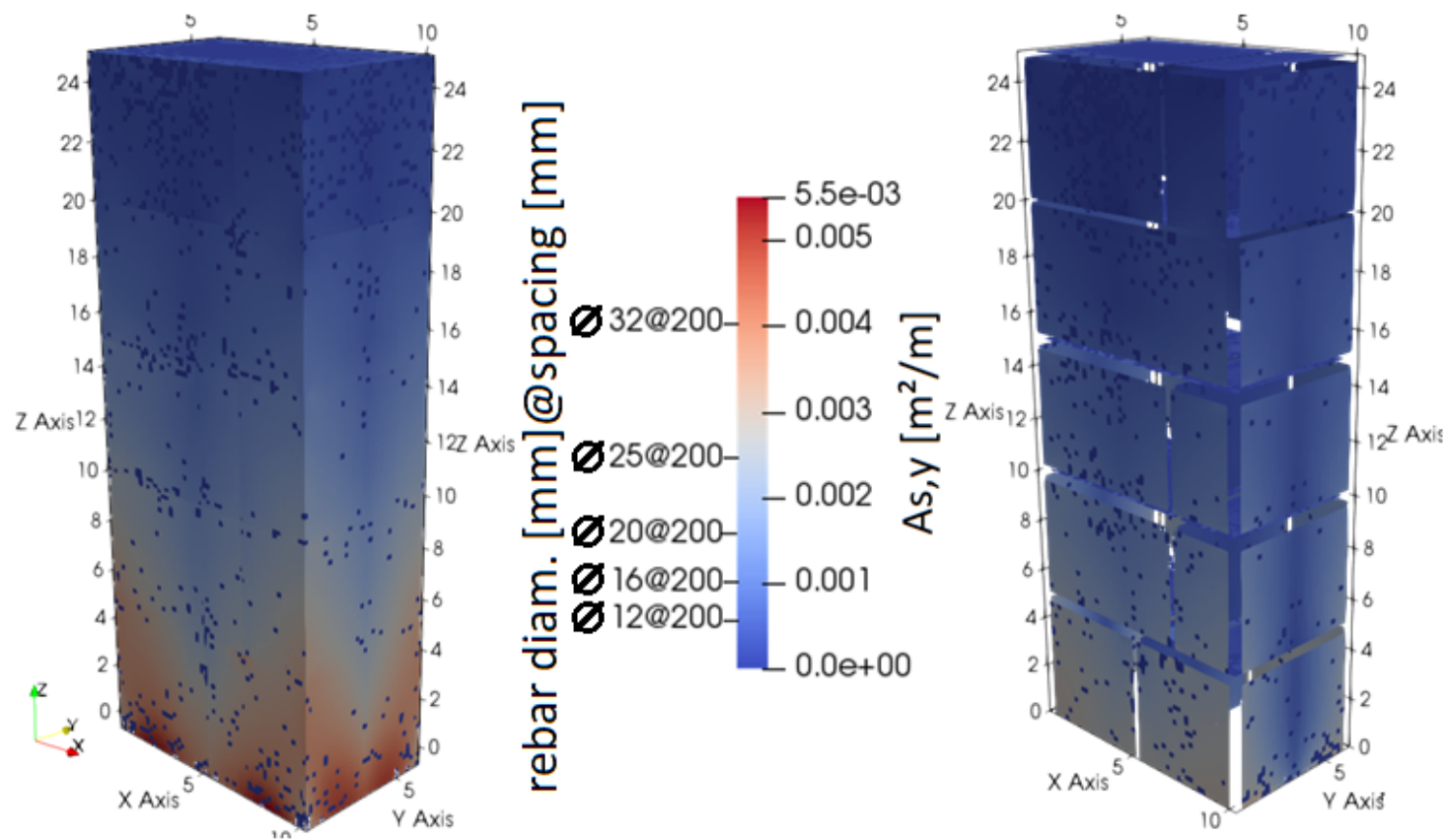

Figure 18: Reinforcement sections computed for both models to cover the 24 Newmark seismic loads combinations, with accidental Ultimate Limit State criteria - Usual practice on the left - Enhanced proposed modeling on the right

In order to quantitatively measure the need for reinforcement and to identify the potential impact on constructability, the distribution of reinforcement sections and the density of reinforcement are assessed using a simple descriptive statistics method. The relative distribution of the populations of 
reinforcement sections was studied (Figure 19) over 100 classes distributed between 0 and the maximum value of the reinforcement considered for the two types of modeling.
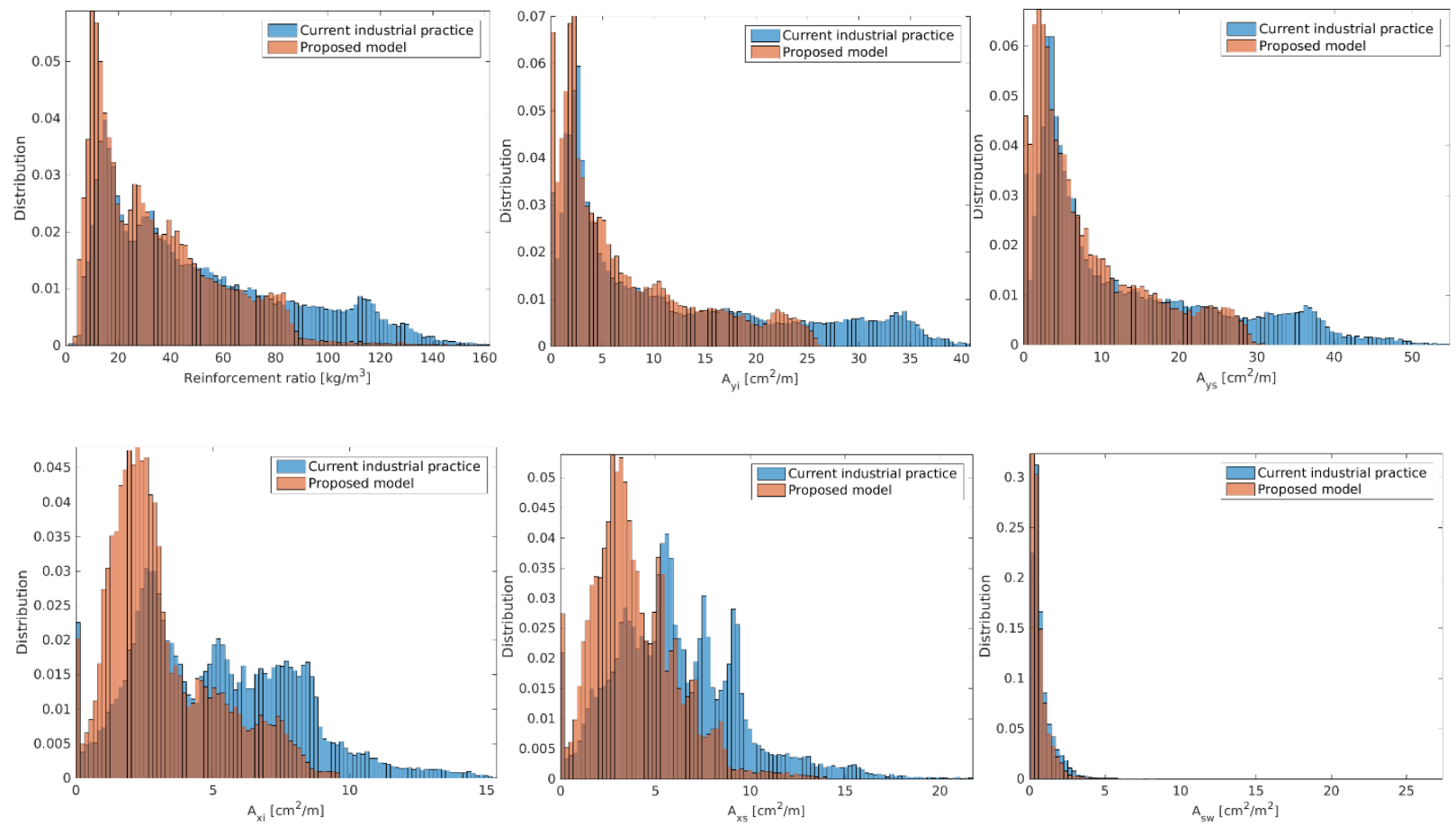

Figure 19: Descriptive statistics overview of the results: reinforcement ratio (a), reinforcement in Y-direction respectively on upper (a) and lower faces, reinforcement in $X$-direction respectively on lower and upper face, shear transverse reinforcement - "Current industrial practice" stands for practice based on plate model

The reinforcement ratio helps to grasp the overall consequences of the optimization of the quantity of reinforcement. In the example, the distribution of the reinforcement has been gathered on the lower values. The optimization of bending reinforcement is the most significant. The singularities of the connections that the kinematics has smoothed are improved due to the impact of the elements presented in section 5.1. The repeated peaks in bending reinforcement distribution curves are associated with the connections at each floor of the building.

For one of the external walls, a schedule of the reinforcement by level is estimated in Table 6 . 
Table 6: Longitudinal reinforcement diameters in mm every $20 \mathrm{~cm}$ computed with the two models, for the external VY3 wall (wall located at $\mathrm{x}=10.3 \mathrm{~m}$ ) - B500B grade steel

\begin{tabular}{|c|c|c|c|c|c|c|c|c|}
\hline \multirow{2}{*}{ Level } & \multicolumn{4}{|c|}{ Usual practice model } & \multicolumn{4}{c|}{ Proposed hybrid model } \\
\cline { 2 - 11 } & $\begin{array}{c}\text { Vertical - } \\
\text { external } \\
\text { face }\end{array}$ & $\begin{array}{c}\text { Vertical - } \\
\text { internal } \\
\text { face }\end{array}$ & $\begin{array}{c}\text { Horiz. }- \\
\text { external } \\
\text { face }\end{array}$ & $\begin{array}{c}\text { Horiz. } \\
\text { internal } \\
\text { face }\end{array}$ & $\begin{array}{c}\text { Vertical - } \\
\text { external } \\
\text { face }\end{array}$ & $\begin{array}{c}\text { Vertical - } \\
\text { internal } \\
\text { face }\end{array}$ & $\begin{array}{c}\text { Horiz. - } \\
\text { external } \\
\text { face }\end{array}$ & $\begin{array}{c}\text { Horiz. - } \\
\text { internal } \\
\text { face }\end{array}$ \\
\hline 1 & $\varnothing 32+\varnothing 20$ & $\varnothing 32$ & $\varnothing 20$ & $\varnothing 20$ & $\varnothing 32 / 25$ & $\varnothing 25$ & $\varnothing 20$ & $\varnothing 20$ \\
\hline 2 & $\varnothing 32$ & $\varnothing 32 / 25$ & $\varnothing 16$ & $\varnothing 16$ & $\varnothing 25$ & $\varnothing 25$ & $\varnothing 16$ & $\varnothing 16$ \\
\hline 3 & $\varnothing 25$ & $\varnothing 25$ & $\varnothing 16$ & $\varnothing 16$ & $\varnothing 20$ & $\varnothing 20$ & $\varnothing 16$ & $\varnothing 16$ \\
\hline 4 & $\varnothing 20$ & $\varnothing 20$ & $\varnothing 16$ & $\varnothing 16$ & $\varnothing 16$ & $\varnothing 16$ & $\varnothing 16$ & $\varnothing 16$ \\
\hline 5 & $\varnothing 12$ & $\varnothing 12$ & $\varnothing 12$ & $\varnothing 12$ & $\varnothing 12$ & $\varnothing 12$ & $\varnothing 12$ & $\varnothing 12$ \\
\hline
\end{tabular}

For the entire wall, mainly loaded in bending by seismic actions, the proposed hybrid model enables a reduction in the longitudinal reinforcement of $25 \%$. The reduction is significantly smaller, or almost nil, on structural elements working mainly in membrane traction (floors or inner walls of lower thickness). No minimum reinforcement criteria were considered here. The application of a minimum reinforcement criterion on the considered wall would reduce de facto the optimization that could be achieved regarding the quantities of reinforcement as computed quantities fall below the corresponding threshold.

This example illustrates that the improvement proposed to the modeling of $\mathrm{D}$ regions within the structure (massive zones, connections) is feasible at the scale of a nuclear building and led to the expected optimization in terms of reinforcement, in accordance with section 5.1.

It should be highlighted that the use of such optimized computation methods at the early design stage, especially for nuclear buildings, should be accompanied by the application of deliberate design reinforcement provisions. These provisions are dedicated to cover future project developments in case of seismic retrofitting, for example, so that the installations' high level of safety is maintained. 
The key benefit of this optimization is that the uncertainty linked to inappropriate modeling is considerably reduced. Thus, the reinforcement provisions can be carried out through a deterministic, or even a probabilistic approach, with a chosen and well-known level.

\section{Conclusions}

The developments presented in this article share one common objective: provide a rationale to optimize the quantity of reinforcement actually needed in a nuclear concrete structure. Improving finite element calculation without considering the post-processing of the quantities of interest is not worthwhile. No industrial practitioner is expected to endorse the proposed improvement if automation cannot be implemented. If one does not anticipate the best way to generate the quantities of interest, any methodological improvement in post-processing is also meaningless, as the initial result will contain so many errors that the final result will not be reliable.

To this end, a comprehensive modeling strategy is proposed from the finite element modeling assumptions to the post-processing. An overall method is the only way to cope with the issue of excessive reinforcement. If adopted, one should note that this modeling strategy is fully compatible with and can be easily plugged into digital mock-ups. Thus, it can accelerate the transfer between Computer-Aided Design, FEM calculations, and reinforced concrete structures design.

In this work, the following questions have been addressed and developed in the code_aster FEM software (code_aster, 2020):

- Proposing a way to model B and D regions and their interface using specific connection finite element kinematical constraints adapted to the actual geometry of the joint,

- Improving the post-processing of B regions using an upscaling approach that can increase the generation of reinforcement schedule and smooth the rebar quantities,

- Summarizing the existing approaches to post-process D regions to automate the use of the strut-and-tie method. 
Through a proof-of-concept study carried out on a simplified building, it has been shown the benefits of hybrid modeling involving both bricks and plate/shell finite elements connected through kinematical relations. The gains consist of a $25 \%$ saving in reinforcement due to bending.

A particular academic example has been provided to demonstrate a new approach based on the localglobal concept to smooth the reinforcement needs by considering a field transfer method that conserves the potential energy. The proposed approach enables the automatic identification of homogenized panels considering an indicator based on the quadratic sum of the curvature of the midplane of the plates.

These developments and tests have been carried out using the EDF in-house open-source FEM opensource software code_aster (code_aster, 2020).

Some points are still under development and will be addressed in the coming years:

- D region: the automation of the strut-and-tie method will also need to take account of several combinations to determine the reinforcement needs that are optimal for the whole set of combinations,

- B region: the indicator used to generate the seeds of the local-global method is currently being challenged as well as the optimum size of the Voronoi tessellation through a set of numerical tests.

Adding a perspective to this strategic vision, it should be specified that these substantial modeling efforts may be completed to reach the final performance-based design philosophy by accounting for uncertainty and variability in the overall process.

\section{Acknowledgments}

Authors wish to acknowledge Electricité de France, R and D Division, Geodynamique and Structures Company, and Université Paris-Saclay for this research's financial and material support. 


\section{REFERENCES}

\section{- Références}

Almeida, V. S., Simonetti, H. L., \& Neto, L. O. (2013). Comparative analysis of strut and tie models using smooth evolutionary structural optimization. Engineering and Structures, 1665-1675.

Aurenhammer, F., Klein, R., \& Lee, D. T. (2013). Voronoi diagrams and Delaunay triangulations. World Scientific Publishing Company.

Ben Dhia, H. (1998). Problèmes mécaniques multi-échelles: la méthode Arlequin. Comptes Rendus de I'Académie des Sciences - Series IIB - Mechanics-Physics-Astronomy, 899-904.

Bendsoe, M. P., \& Sigmund, O. (2003). Topology optimization: theory, methods and applications.

Capra, A., \& Maury, J.-F. (1978). Calcul automatique du ferraillage optimal des plaques et coques en béton armé. Annales de l'Institut Technique du Bâtiment et des travaux publics, $\mathrm{n}^{\circ} 367$.

code_aster. (2020, october 15). code_aster. Récupéré sur code_aster - Structures and thermomechanics analysis for studies and research: www.code-aster.org

Deleuze, G. (1967). Réponse à un mouvement sismique d'un édifice posé sur un sol élastique. Annales de I'ITBTP, 234.

Eleftheriadis, S., Duffour, P., Stephenson, B., \& Mumovic, D. (2018). Automated specification of steel reinforcement to support the optimisation of RC floors. Automation in construction, 366-377.

El-Metwally, S.-D., \& Chen, W. (2018). Structural Concrete - Strut-and-Tie Models for Unified Design. Taylor \& Francis.

EN1992-1-1:2004. (2004). Eurocode 2: Design of concrete structures - Part1-1: General rules and rules for buildings. CEN.

ETC-C. (2010). ETC-C: EPR Technical Code for Civil Works. AFCEN.

Gaynor, A. T., Guest, J. K., \& Moen, C. D. (2013). Reinforced Concrete Force Visualization and Design UsingBilinear Truss-Continuum Topology Optimization. Journal of Structural Engineering, 139:607-618.

Gazetas, G. (1991). Formulas and charts for impedances of surface and embedded foundations. Journal of Geotechnical Engineering, Vol. 117, Issue 9.

Hervé, G., Cloitre, L., El Kadiri, S., Secourgeon, E., Masini, D., Mennela, G., \& Carême, C. (2014). Comparative study of shell element and brick element models for NPP structures. Technological Innovations in Nuclear Civil Engineering. Paris.

Hervé, G., Cloitre, L., El Kadiri, S., Secourgeon, E., Masini, D., Mennela, G., \& Carême, C. (2014). Parametric study of shell models for NPP structures. Technological Innovations in Nuclear Civil Engineering. Paris.

Hervé-Secourgeon, E. (2020, June). Ph.D. Thesis. Caractérisation et modélisation du comportement des jonctions voile-plancher en béton armé pour l'analyse sismique des ouvrages de Génie Civil et des équipements, Université Paris-Saclay.

Hervé-Secourgeon, E., Voldoire, F., Gatuingt, F., Oliver-Leblond, C., Hervé-Secourgeon, G., Escoffier, F., Guilloux, A., Chaudat, T.,Wang, F. (2019). Caractérisation expérimentale et modélisation numérique des jonctions voile-plancher dans les structures en béton armé sous séisme. Colloque AFPS. Strasbourg.

Ibrahimbegovic, A., Hervé, G., \& Villon, P. (2009). Nonlinear impact dynamics and field transfer suitable for parametric design studies. Engineering Computations, Vol. 26 No. 1/2, pp. 185204.

Jewett, J. L., \& Carstensen, J. V. (2019). Experimental investigation of strut-and-tie layouts in deep RC beams designed with hybrid bi-linear topology optimization. Engineering Structures, Volume 
197.

Liang, Q. Q., \& Xie, Y. M. (2000). Topology Optimization of Strut-and-Tie Models in Reinforced Concrete Structures Using an Evolutionary Procedure. ACI Structural Journal, V. 97, No. 2.

Marti, P. (1991). Dimensioning and detailing. IABSE Colloquim Report, (pp. 411-443). Stuttgart.

Mendoza-Chavez, G. (2018, July). Strut-and-Tie models for the design of non-flexural elements: computational aided approach. University of Paris-Est.

Muttoni, A., Fernàndez Ruiz, M., \& Niketic, F. (2015). Design versus Assessment of Concrete Structures Using Stress Fields and Strut-and-Tie Models. ACI Structural Journal, 12(5), 605-616.

Qiao, H., Yang, Q., Chen, W., \& Zhang, C. (2011). Implementation of the Arlequin method into ABAQUS: Basic formulations and applications,. Advances in Engineering Software, 197-207.

RCC-CW. (2019). Rules for Design and Construction of PWR Nuclear Civil Works. AFCEN.

RCC-G. (1989). RCC-G: Règles de conception et de construction du génie civil des îlots nucléaires REP. AFCEN.

Sigmund, O. (2001). A 99 line topology optimization code written in Matlab. Structural Multidisciplinary Optimization, 120-127.

Sotiropoulos, S., \& Lagaros, N. D. (2020). Topology Optimization of Framed Structures using SAP2000. Procedia Manufacturing, Pages 68-75, Volume 44.

Voronoï, G. (1908). Nouvelles applications des paramètres continus à la théorie des formes quadratiques. Premier mémoire. Sur quelques propriétés des formes quadratiques positives parfaites. Journal für die Reine und Angewandte Mathematik, 198-287.

Wood, R. (1968). The reinforcement of slabs in accordance with a pre-determined field of moments. Concrete, 66-79. 